Copyright (C) 2016-2019. This material is presented to ensure timely dissemination of scholarly and technical work. Copyright and all rights therein are retained by authors or by other copyright holders. All persons copying this information are expected to adhere to the terms and constraints invoked by each author's copyright. In most cases, these works may not be reposted without the explicit permission of the copyright holder.

The following article is the POST-PRINTS version. An updated version will be available when the article is fully published. If you do not have access, you may contact the authors directly for a copy.

The current reference for this work is as follows:

A. J. Burns, Tom L. Roberts, Clay Posey, and Paul Benjamin Lowry (2019). “The adaptive roles of positive and negative emotions in organizational insiders' engagement in security-based precaution taking," Information Systems Research (ISR) (accepted 21-Feb-2019).

If you have any questions, would like a copy of the final version of the article, or would like copies of other articles we've published, please contact any of us directly, as follows:

- Dr. A. J. Burns

○ Management Information Systems, Hankamer School of Business, Baylor University

- Email: AJ_Burns@baylor.edu

- Website: http://business.baylor.edu/directory/?id=AJ Burns

- Professor Tom L. Roberts

- Professor of Computer Science

- Department: Computer Science

- University of Texas at Tyler

- Email: troberts2@uttyler.edu

o Website: http://www.uttyler.edu/directory/cs/troberts.php

- Dr. Clay Posey

○ University of Central Florida

○ Email: Clay.Posey@ucf.edu

- Website: https://business.ucf.edu/person/michael-clay-posey/

- Professor Paul Benjamin Lowry

- Suzanne Parker Thornhill Chair Professor in Business Information Technology

- Pamplin College of Business, Virginia Tech, USA

○ Email: Paul.Lowry.PhD@gmail.com

○ Website: https://sites.google.com/site/professorlowrypaulbenjamin/home

- System to request Paul's articles: https://seanacademic.qualtrics.com/SE/?SID=SV 7WCaP0V7FA0GWWx 


\title{
The Adaptive Roles of Positive and Negative Emotions in Organizational Insiders' Security-Based Precaution Taking
}

\begin{abstract}
Protecting organizational information is a top priority for most firms. This reality, coupled with the fact that organizational insiders control much of their organizations' valuable information, has led both researchers and practitioners to acknowledge the importance of insiders' behavior for information security (InfoSec). Until recently, researchers have employed only a few theories to understand these influences, and this has generated calls for a broadened theoretical repertoire. Given this opportunity, we incorporate the framework of emotions developed in the information systems (IS) discipline by Beaudry and Pinsonneault (2010) and add the broaden-and-build theory (BBT) to understand the influence of discrete positive and negative emotions on insiders' precaution-taking activities. Our findings demonstrate that the relationship between both positive and negative emotions and precaution taking is mediated by insiders' (1) psychological capital (PsyCap), a higher-order, work-related construct of positive psychological resource capabilities, and (2) psychological distancing, a coping mechanism characterized by insiders' attempts to detach themselves psychologically from a situation. By considering these factors, our model explains 32 percent of the variance in insiders' precaution taking in organizations. Researchers and practitioners can use these findings to develop effective insider InfoSec training, including emotional appeals that increase insiders' precaution taking.
\end{abstract}

\section{KEYWORDS}

Information security (InfoSec); organizational security; emotions; precaution taking; broaden-and-build theory (BBT); positive psychology; psychological distancing; psychological capital (PsyCap) 


\section{INTRODUCTION}

Whether positive or negative, the tremendous influence of individuals' behavior on organizational information security (InfoSec) is widely accepted by both academics and practitioners (Boss et al. 2015; Crossler et al. 2013; D’Arcy et al. 2014; Hsu et al. 2015; Posey et al. 2013; Vance et al. 2013, 2015; Willison \& Warkentin 2013). This realization has generated the emergence of behavioral and organizational InfoSec research (hereafter, "InfoSec research"), generally defined as the study of human actions that influence the security of organizational information systems (IS). A major premise of contemporary InfoSec research is that organizational insiders - agents of the firm, such as employees, contract workers, and board members (Posey et al. 2013) — can influence InfoSec within firms both positively and negatively by virtue of their access to information resources (Warkentin \& Willison 2009). Whereas some behaviors involve the use of protective technologies, many others involve nontechnical means of protecting sensitive information and associated systems (Posey et al. 2013).

Increased reliance on insiders is key to InfoSec evolution within organizations. Surveys indicate that many insiders feel a responsibility to take precautions against InfoSec threats, but relatively few employees feel confident in their ability to actually protect their firms (Dell 2017). This tension between emotion and practice is important: How employees feel about opportunities to take InfoSec precautions (i.e., their emotional reaction) plays an important role in galvanizing their intrinsic motivation to take action (Lazarus 1991). InfoSec, then, is not merely a cognitive exercise involving pure, rational thought. For example, encountering an opportunity to take responsibility for their organization's InfoSec might elicit positive emotions when the insider feels that doing so is an important part of their duties. When insiders feel uncertain about how to proceed in taking precautions, however, negative emotions might emerge simultaneously. This emotional tension can obscure the understanding of insiders' intrinsic motivations, and thus their ability to parse the unique influences associated with the various emotions becomes paramount.

As InfoSec researchers expand their theoretical repertoire beyond traditional deterrence and protection-motivation theories to more fully understand the role of insiders in organizational InfoSec 
(Crossler et al. 2013; Willison \& Warkentin 2013), we contend that the systematic study of insiders' emotions and the influence of those emotions on InfoSec-related behavior presents a promising research opportunity. Emotions are a fruitful area of investigation because they act as an adaptive intermediary between stimuli and behavior (Lazarus 1991). Emotion is a manifestation of a person-environment relationship, and "the basic unit of this relationship is an adaptational encounter or episode" (Lazarus 1991, p. 29). As organizations are assailed with ever-evolving InfoSec threats, insiders are increasingly faced with adaptational encounters (Baskerville et al. 2014; Dlamini et al. 2009; Hamill et al. 2005).

Although the study of emotions in InfoSec research is still nascent, InfoSec researchers have considered the role of emotions and emotion-related factors such as stress (e.g., D'Arcy et al. 2014), reactance (e.g., Lowry \& Moody 2015; Lowry et al. 2015b), and fear (e.g., Boss et al. 2015; Johnston \& Warkentin 2010; Warkentin et al. 2016) in determining important security-related intentions and behaviors. D'Arcy et al. (2014) investigated emotion-focused coping in response to stressful security policies, and Warkentin et al. (2016) examined insiders' fear responses to InfoSec threats. Despite such compelling studies of emotions, InfoSec research lacks a coherent framework for considering the roles of both positive and negative emotions in behavioral adaptation. Moreover, few studies have examined positive and negative emotions concurrently. Instead, most organizational and InfoSec research has addressed only the role of negative emotions (e.g., Fredrickson 1998; Johnston \& Warkentin 2010). A more comprehensive treatment of emotion in InfoSec research is necessary because emotional stimuli often simultaneously elicit positive and negative emotions of varying intensities that then influence behaviors (Beaudry \& Pinsonneault 2010; Lazarus 1991; Lazarus \& Folkman 1984). This overlap of emotions complicates the study of insiders' motivations, as each emotion plays a unique role in influencing behavior (Lazarus 1991), and InfoSec researchers have yet to adopt a holistic view of how insiders' emotions influence the protection of information assets.

To bridge this research gap, we focus on the influence of insiders' emotions on InfoSec precaution taking. Such precautions capture the essence of in-role (i.e., required) and extra-role (i.e., proactive) behaviors that employees should demonstrate to protect their organizations from InfoSec 
threats. These precautions are crucial, as research has shown that InfoSec is enhanced when insiders take in- and extra-role measures to protect firms from security threats (Hsu et al. 2015; Posey et al. 2013). Merriam-Webster defines precaution as "a measure taken beforehand to prevent harm or secure good" (Merriam-Webster n.d.), while the Cambridge Dictionary defines it as "an action taken to prevent something unpleasant or dangerous from happening" (Cambridge Dictionary n.d.). Sandin (2004, p. 467) augments these definitions by detailing three criteria for precaution: (1) intentionality, when a precaution is taken to prevent an undesirable event or outcome; (2) uncertainty, when the individual taking precautions is unsure whether a certain undesirable event or outcome will occur; and (3) reasonableness, when the individual taking precautions believes (a) that the undesirable event or outcome may occur, (b) that the precaution, if taken, will at least contribute to its avoidance, and (c) that the undesirable event may not occur even if the precaution is not taken.

For this study, precaution taking is defined as the degree to which employees take both technical and behavioral measures to secure organizational information assets against threats, both through prescribed security policies and procedures and through discretionary proactive actions (Boss et al. 2009). Implied in our definition is the reality that precaution taking is always in response to a perceived threat, thus amplifying the potential role of emotions in precaution taking. We base our study of how positive and negative emotions affect insiders' precaution-taking activities largely on advances in the positive psychology movement and on the broaden-and-build theory (BBT) (Fredrickson 1998, 2001; Fredrickson \& Branigan 2005). Positive psychology addresses "the conditions and processes that contribute to the flourishing or optimal functioning of people, groups, and institutions" (Gable \& Haidt 2005, p. 103). The BBT posits that positive emotions "broaden the scope of attention and thought-action repertoires" (Fredrickson \& Branigan 2005, p. 313) while simultaneously building lasting psychological resources (Fredrickson 1998, 2001; Fredrickson \& Branigan 2005). A thought-action repertoire is the set of thoughts and behaviors cognitively available to an individual at the time of behavioral adaptation (Fredrickson \& Branigan 2005).

To examine the direct and indirect adaptive influences of emotions on InfoSec, we develop and 
empirically test a model of emotions based on an extension and integration of the emotions framework (Beaudry \& Pinsonneault 2010) and the BBT (Fredrickson 1998, 2001). We show that two mediators affect the positive and negative emotions elicited in response to the protection of organizational information assets. Our study is crucial for InfoSec research and practice because these emotions serve as adaptive intermediaries between insiders' exposure to stimuli and their resulting InfoSec-related behavior. Organizations' failure to account for insiders' broad experience of emotions when dealing with InfoSec threats introduces vulnerability, because the resulting adaptive response to this experience can interrupt the expected stimulus-response relationship.

\section{BACKGROUND ON EMOTIONS}

It is inconceivable to me that there could be an approach to the mind, or to human and animal adaptation, in which the emotions are not a key component. Failure to give emotion a central role puts theoretical and research psychology out of step with human preoccupations from the beginning of recorded time (Lazarus 1991, p. 4).

IS research continues to adapt to the evolving role of technology in individuals' lives, the modern workplace, and society. Accordingly, researchers have advocated adding adaptive mechanisms to the IS theoretical repertoire (Abraham et al. 2013; Willison \& Warkentin 2013). One principal tenet of adaptation is the evolutionary concept of survival of the fittest. The organizational and economic implications of this philosophy in InfoSec research are widespread, from the survival of the fittest firm (Gimeno et al. 1997) to the adoption of the fittest technology (Hantula et al. 2011; Kock 2009). From an evolutionary perspective, emotions play an adaptive role in fitness enhancement (Nesse \& Ellsworth 2009). Negative emotions adapt positively when fitness is challenged, and vice versa: Positive emotions are elicited by stimuli that are motive consistent, and negative emotions are prompted by stimuli that are motive inconsistent (Éthier et al. 2006). Emotions then elicit innate or adaptive responses that have generally supported the survival of the human species (Nesse \& Ellsworth 2009). Emotions can thus be viewed as either innate coping mechanisms or evolved adaptive responses.

Given the relationship between emotions and innate or adaptive responses, we contend that emotion and coping literature offers a promising perspective for the study of insiders' IS-related 
adaptation (Beaudry \& Pinsonneault 2005). Moreover, the BBT (Fredrickson 1998, 2001) provides a complementary explanation of the complex relationship between emotional stimuli and adaptation, elucidating the role of emotions (both positive and negative) in human cognition, behavior, and psychological resources.

\subsection{Framework of Emotions}

In the IS context, Beaudry and Pinsonneault (2010) developed a framework for classifying discrete emotions based on the work of Lazarus and colleagues (Folkman et al. 1986; Lazarus \& Folkman 1984). The distinction between discrete emotions and other affective states, such as sensory pleasure and positive mood, is that emotions — both positive and negative — have a specific referent (Beaudry \& Pinsonneault 2010; Lazarus 1991; Smith \& Lazarus 1990; Zhang 2013). ${ }^{i}$ In IS research, the comprehensive role of discrete emotions in dealing with organizational InfoSec threats has yet to be fully examined. To this end, Beaudry and Pinsonneault's (2010) seminal work on emotion classification informs our research, but we diverge from that work in at least two key ways. First, rather than focus on information technology (IT) adoption, we examine precaution taking, which introduces the threat of danger and/or undesirable consequences for individuals, organizations, and constituencies. The precautions taken by employees could determine the future success or demise of their organizations. The distinction between IT adoption and InfoSec precaution taking is crucial because precaution taking encompasses a broad-based response to diverse InfoSec threats. As prior researchers explain, InfoSec encounters are particularly laden with emotion (D'Arcy et al. 2014) due to their potentially serious consequences. Second, the previous assessment of the emotions framework involved one model for positive emotions and another for negative emotions (Beaudry \& Pinsonneault 2010). Our research focuses on a more comprehensive model in which positive and negative emotions coexist and influence behavioral outcomes concurrently. Finally, we are among the first to examine the simultaneous mediation of positive and negative emotions by distinct psychological mechanisms such as individuals' psychological capital (PsyCap) and psychological distancing.

Explaining the elicitation of discrete emotions, Lazarus and Folkman (1984) described a coping 
process for people confronted with "any event in which the person feels his or her adaptive resources to be taxed or exceeded" (p. 27). Taxing stimuli initiate a two-stage appraisal process: a primary and a secondary appraisal (Lazarus \& Folkman 1984). During the primary appraisal, an individual assesses the stimulus as either irrelevant, benign/positive, or stressful, whereas during the secondary appraisal, individuals evaluate their ability to control the results of the stimulus. Stressful appraisals can then be further categorized as being a harm/loss, a threat, or a challenge (Lazarus \& Folkman 1984). Figure 1 shows the role of primary and secondary appraisals in Beaudry and Pinsonneault's (2010) framework of emotions.

Figure 1. Framework of Emotions Adapted from Beaudry and Pinsonneault (2010) Opportunity

\begin{tabular}{|c|c|c|c|}
\hline \multirow{2}{*}{$\begin{array}{l}\text { Perceived lack of } \\
\text { control over expected } \\
\text { consequences }\end{array}$} & $\begin{array}{l}\text { Achievement Emotions } \\
\text { Examples: } \\
\text { •Happiness } \\
\text {-Satisfaction } \\
\text {-Pleasure } \\
\text { - Relief } \\
\text {-Enjoyment }\end{array}$ & $\begin{array}{l}\text { Challenge Emotions } \\
\text { Examples: } \\
\text { •Interest } \\
\text { • Hope } \\
\text {-Anticipation } \\
\text {-Arousal } \\
\text { •Playfulness } \\
\text { •Excitement } \\
\end{array}$ & \multirow{2}{*}{$\begin{array}{l}\text { Perceived control } \\
\text { over expected } \\
\text { consequences }\end{array}$} \\
\hline & $\begin{array}{l}\text { Loss Emotions } \\
\text { Examples: } \\
\text {-Sadness } \\
\text {-Anger } \\
\text {-Dissatisfaction } \\
\text {-Annoyance } \\
\text { - Frustration } \\
\text {-Disgust }\end{array}$ & $\begin{array}{l}\text { Avoidance Emotions* } \\
\text { Examples: } \\
\text { •Anxiety } \\
\text { •Fear } \\
\text { •Worry } \\
\text { •Distress } \\
\text { *Originally termed "deterrence emotions." }\end{array}$ & \\
\hline
\end{tabular}

In addition to its incorporation of primary and secondary appraisals, Beaudry and Pinsonneault's (2010) framework is insightful in its depiction of discrete emotions, because experiences of emotions often overlap and vary in intensity (Lazarus \& Folkman 1984). The framework categorizes emotions as either positive (above the $\mathrm{x}$-axis) or negative (below the $\mathrm{x}$-axis). This distinction illuminates their influence on insiders, as positive and negative emotions are relatively independent and thus influence behavior and cognition differently (Bagozzi et al. 1999; Cenfetelli 2004; Fredrickson 2001). When stimuli are appraised as enhancing fitness (i.e., an opportunity), the emotions elicited have a positive valence, whereas a stimulus assessed as challenging fitness (i.e., a threat) elicits negative emotions (Beaudry \& Pinsonneault 2010; Nesse \& Ellsworth 2009). In this way, the framework illustrates the complementary relationship between appraisal theories of emotion and adaptive approaches to emotion (Nesse \& 
Ellsworth 2009).

Beaudry and Pinsonneault's (2010) original emotions framework classifies the negative emotions associated with controllable consequences (e.g., anxiety, fear, worry, distress) as deterrence emotions. However, the term deterrence is potentially confusing in this context because it is often used in InfoSec studies to refer to sanctions (e.g., D’Arcy \& Herath 2011; Willison \& Warkentin 2013) rather than emotions; thus, we refer to the bottom-right quadrant of the emotions framework as avoidance emotions. This quadrant is associated with an action tendency of avoidance because of the evolutionary flight instinct (Lazarus 1991). Avoidance is an apt description, as these emotions arise when an individual appraises a stimulus as threatening yet perceives control over the outcome (i.e., the consequences are avoidable) (Beaudry \& Pinsonneault 2010; Nesse \& Ellsworth 2009). Therefore, avoidance is an active adaptation due to an implied perception of control (Carver \& Scheier 1982). We assert that adaptation in the face of security threats can be explained as an emotionally adaptive coping response that uniquely elicits discrete emotions across the four quadrants of the emotions framework. We contend that based on their associated action tendencies, the motivational influences of some emotions, although adaptive from an evolutionary perspective, may be organizationally maladaptive in terms of their relationship with insiders' security-related behavior (e.g., precaution taking).

\subsection{The Broaden-and-Build Theory (BBT)}

We use the BBT to explain the role of emotions in behavioral adaptation. This emerging theory is associated with positive psychology, which posits that positive emotions broaden individuals' thoughtaction repertoires and increase their ability to process information through a broadened scope of attention (Fredrickson 2001). Conversely, negative emotions narrow the thought-action repertoire to more immediate and survival-oriented responses (Fredrickson \& Branigan 2005). Over time, positive emotions support the building of lasting psychological resources, such as the process by which curiosity inspires knowledge (Fredrickson 1998, 2001; Fredrickson \& Branigan 2005). Thus, implicit in the BBT are three distinct roles for emotions: broadening, narrowing, and building (Fredrickson \& Branigan 2005). 


\subsubsection{The Broadening Role}

The broadening role of positive emotions influences individuals in two distinct ways. First, positive emotions increase an individual's ability to recognize and process external cues (e.g., they broaden the scope of attention and the ability to process information). Second, they expand an individual's thought-action repertoire. A widened scope of attention and cognitive processing is congruent with Isen's (1999) assertion that positive affect generally strengthens “memory, learning, problem solving and creativity, and flexibility in thinking" (p. 521). A broadened scope of attention also increases cognitive variation, which can increase the number of original ideas (Amabile et al. 2005). Likewise, creative problem-solving results when individuals expand their processing of the conditions related to an issue (Amabile et al. 2005; Fredrickson 2004). Thus, as employees increasingly seek to protect their firms through their use of and interactions with the firms' IS (Boss et al. 2009; Hsu et al. 2015; Posey et al. 2013), the increased cognitive agility and broadened information processing generated by positive emotions should provide insiders with key InfoSec resources (Amabile et al. 2005; Fredrickson 2004; Fredrickson \& Branigan 2005; Isen 1999).

Positive emotions also extend an individual's thought-action repertoire - the set of thoughts and actions accessible at a given moment regarding a behavioral stimulus (Fredrickson \& Branigan 2005). Insiders' enactment of the protection-motivated behaviors (PMBs) associated with diverse security roles, as identified by Posey et al. (2013), is contingent upon the scope of their thought-action repertoires at the time of the behavioral stimulus (e.g., the threat). Given the rapidly evolving threats facing insiders in contemporary firms (Baskerville et al. 2014), their precaution taking should be enhanced by experiencing certain discrete positive emotions. In this way, the BBT offers a partial remedy for the "knowing-doing" gap of security behaviors (Workman et al. 2008) by explaining that security-related thinking and behavioral diversity are augmented by positive emotions.

\subsubsection{The Narrowing Role}

The BBT explains that negative emotions play a narrowing role (Fredrickson \& Branigan 2005), but this role does not imply an inverse relationship between positive and negative emotions. Rather, 
positive and negative emotions influence cognition and behavior in altogether independent ways (Isen 1999). This is similar to a relationship discovered in recent research that demonstrates how trust and distrust, instead of lying at opposite ends of the same spectrum, are distinct constructs that can operate concurrently (e.g., Lowry et al. 2015c; Moody et al. 2014). The narrowing effect of negative emotions is deeply rooted in the adaptive role of emotions: Negative emotions elicit specific action tendencies based on adaptive needs (Cosmides \& Tooby 2000; Fredrickson \& Branigan 2005). Many of these adaptive tendencies evolved from mechanisms for improving fitness and, therefore, the likelihood of survival (Cosmides \& Tooby 2000; Nesse \& Ellsworth 2009; Öhman \& Mineka 2001). When fitness is threatened, negative emotions such as fear and anxiety may be stimulated, thus producing a state of readiness for a specific action, such as flight (Bagozzi et al. 1999; Nesse \& Ellsworth 2009). In this way, as predicted by the BBT, the specific tendency prompted by anxiety narrows the thought-action repertoire of the individual experiencing the negative emotion (Fredrickson 1998, 2001).

\subsubsection{The Building Role}

The BBT predicts that positive emotions support the building of significant, lasting psychological resources—-such as resilience, optimism, and creativity—over time (Fredrickson 1998, 2001). Thus, the BBT is a framework of positive emotions rooted in positive psychology (Fredrickson 2001). Seligman and Csikszentmihalyi (2000) outlined the positive characteristics associated with positive psychology as hope, well-being, optimism, and happiness. Fredrickson and Joiner (2002) noted that experiences of positive emotions generate an "upward spiral" toward lasting psychological resources. The core psychological resources of positive psychology are now understood in terms of an individual's PsyCapa work-related, role-breadth construct of positive psychological resource capabilities that are open to development (Luthans et al. 2007a).

\section{THEORETICAL MODEL AND HYPOTHESES}

Employing the BBT and the framework of emotions, we have developed and examined a research model for investigating the influence of emotion on insiders' precaution taking. In the next section, we present a set of hypotheses related to this influence. We then formally test our core theoretical assumption that the 
powerful, indirect influence of emotions extends to insiders' precaution taking. Specifically, we contend that PsyCap and psychological distancing are key mediating links in this model. Psychological distancing represents the effort to "direct one's attention away from the situation and detach oneself from it" (Beaudry \& Pinsonneault 2010, p. 699). Figure 2 depicts the full model.

\section{Figure 2. Research Model}

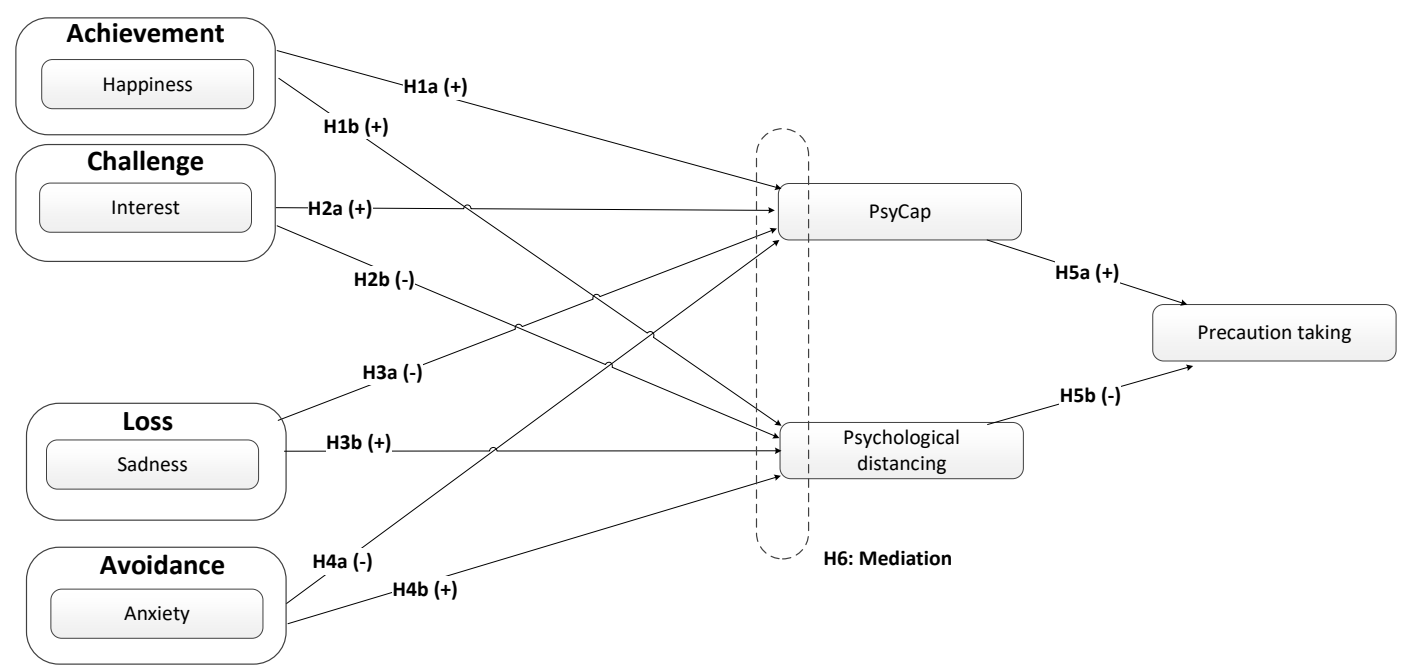

\subsection{Emotion}

Each quadrant in Beaudry and Pinsonneault's (2010) framework contains a set of distinct but related emotions. For concision and control, we have chosen four highly common emotions to represent each category. These discrete emotions are happiness (an achievement emotion), interest (a challenge emotion), sadness (a loss emotion), and anxiety (an avoidance emotion). Figure 3 summarizes the emotions selected from each quadrant of the framework.

\section{Figure 3. Emotions in Research Model}

\begin{tabular}{|c|c|}
\hline $\begin{array}{l}\text { Achievement Emotion } \\
\qquad \text { Happiness } \\
\text { - Positive emotion } \\
\text { - Perceived lack of control over consequences } \\
\text { - Perceived outcome certainty } \\
\text { - Low activation }\end{array}$ & $\begin{array}{l}\text { Challenge Emotion } \\
\qquad \text { Interest } \\
\text { - Positive emotion } \\
\text { - Perceived control over consequences } \\
\text { - Perceived outcome uncertainty } \\
\text { - High activation }\end{array}$ \\
\hline $\begin{array}{l}\qquad \text { Loss Emotion } \\
\qquad \text { Sadness } \\
\text { - Negative emotion } \\
\text { - Perceived lack of control over consequences } \\
\text { - Perceived outcome certainty } \\
\text { - Low activation }\end{array}$ & 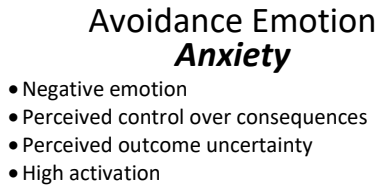 \\
\hline
\end{tabular}




\subsubsection{Happiness as an Achievement Emotion}

Achievement emotions are positive emotions that arise from an appraisal of an opportunity for fitness enhancement that is not accompanied by perceived control over the outcome (Beaudry \& Pinsonneault 2010; Nesse \& Ellsworth 2009). They stem from an individual's perception of a beneficial outcome that results from an eliciting stimulus (Beaudry \& Pinsonneault 2010). The discrete emotion of happiness is a prototypical example of an achievement emotion.

Happiness reflects a high degree of certainty that an outcome will occur without additional effort (Smith \& Ellsworth 1985). Thus, happiness is a "low-activation" emotion that reflects one's satisfaction with a situation that does not require further intervention (Beaudry \& Pinsonneault 2010). Previous research has found that happiness is not related to task adaptation associated with IT use in a firm (Beaudry \& Pinsonneault 2010); that is, whether an individual experienced happiness after an IT implementation in their firm has no relationship with their subsequent adaptation of their behavior to include new capabilities enabled by the new technology. For insiders considering the protection of their firm, the experience of happiness signals an acceptance of the status quo. Happiness is associated with less vigilance (Beaudry \& Pinsonneault 2010). Insiders who are happy with their firms' protective measures are satisfied to reap the rewards of its protection but may not be motivated to take precautions themselves.

\subsubsection{Interest as a Challenge Emotion}

Challenge emotions arise from an appraisal process that classifies an adaptation-related stimulus as an opportunity over which individuals believe they have control (Beaudry \& Pinsonneault 2010). Thus, they are positive emotions that exhibit an apparent fitness-enhancement opportunity (Nesse \& Ellsworth 2009). In describing an individual who has appraised a stimulus as a challenge, Lazarus (1991) noted that a "challenge makes one feel good, and there is apt to be a considerable expansion of one's functioning, with relevant thoughts coming easily and with a subjective impression that one is approaching the zenith of one's powers" (p. 373). Researchers have identified the challenge emotion of interest as an important aspect of intrinsic motivation (e.g., Sansone \& Thoman 2005). Thus, we use interest as the key challenge 
emotion in our model.

The broadened thought patterns noted by Lazarus (1991) that accompany challenge emotions coincide with the "broadening" hypothesis of the BBT (Fredrickson \& Branigan 2005). Perceived control over the stimulus of challenge emotions augments responses generally associated with positive emotions (e.g., approach tendencies) (Cacioppo et al. 1999; Carver \& Scheier 1990). Challenge emotions are linked to increases in task adaptation for individuals who are integrating new IT into their workflow (Beaudry \& Pinsonneault 2010). Specifically, the challenge emotion of interest is associated with a strong desire to take action (Smith \& Ellsworth 1985). Insiders experiencing interest when considering the protection of their firm from InfoSec threats will feel challenged to engage in protective efforts because they feel that they have control over the consequences of the threats. Insiders interested in the protection of their firms' IS are more likely to experience an expanded thought-action repertoire, thus contributing to both the psychological means and the positive intrinsic motivation to engage in proactive precaution taking.

\subsubsection{Sadness as a Loss Emotion}

Loss emotions arise from appraisal of a stimulus as a threat to fitness with uncontrollable consequences (Beaudry \& Pinsonneault 2010; Nesse \& Ellsworth 2009). A typical example of a loss emotion is the discrete emotion of sadness. The inclusion of sadness in our model allows us to assess the emotions framework.

Sadness is associated with an adaptational encounter in which an individual expects a negative (e.g., fitness-reducing) outcome and perceives no control over the consequences (Beaudry \& Pinsonneault 2010). This lack of control situates sadness as a low-activation emotion (Fritz et al. 2010), one that is associated with avoiding future attempts to act (Carver \& Scheier 1982, 1990). Sadness is also related to an inward focus and to behavior immobilization (Lee \& Lang 2009). Contrary to the broadening function of positive emotions, sadness limits the processing of external stimuli (Lee \& Lang 2009). When individuals consider protecting a firm from InfoSec threats, the experience of sadness signals a feeling of helplessness related to the potential consequences of these threats. Sadness is also associated with a narrowed thought-action repertoire, which thereby inhibits insiders' abilities to take effective precautions. 
Sadness is thus associated with a fait accompli, and insiders experiencing this emotion tend to feel that any precautions they take will not change the ultimate outcome.

\subsubsection{Anxiety as an Avoidance Emotion}

Anxiety has received much consideration in IS research, particularly as it relates to computer anxiety (Venkatesh 2000). Although studies have consistently found a negative relationship between computer anxiety and computer self-efficacy (Compeau \& Higgins 1995; Thatcher \& Perrewé 2002), the role of anxiety as a discrete emotion has been noticeably absent from much InfoSec-related research (Chen et al. 2012; D’Arcy et al. 2014; Hwang 2005; Wang et al. 2015).

As an avoidance emotion, anxiety results from a perception that an adaptational encounter will end negatively and that there is some control over the consequences (Beaudry \& Pinsonneault 2010). The BBT posits that negative emotions — including anxiety—narrow individuals' thought-action repertoires (Fredrickson \& Branigan 2005). Thus, avoidance emotions result in more constrained, specific-action tendencies and are linked to individuals' motivations to avoid or escape situations (Liang \& Xue 2009). To enhance the knowledge base regarding anxiety's influence on individuals' precaution taking, we address anxiety associated with protecting the firm from threats. This is a key distinction, as insiders who experience anxiety when considering the protection of their firm will have a narrow thought-action repertoire and will be motivated to avoid the situation. The adaptive role of anxiety in terms of survival may thus produce a maladaptive result for the organization if the situational anxiety relates to the act of protecting the firm from threats (i.e., the adaptational encounter) rather than the threat itself. Anxiety related to a threat may prompt insiders to deter the threat by taking precautions; however, anxiety associated with the act of protecting the firm may prompt insiders to avoid taking precautions.

\subsection{The Mediated Relationship of Emotions through PsyCap}

The BBT explains that emotions influence individuals' psychological resources, such as those embodied in PsyCap (Fredrickson 1998, 2001; Fredrickson \& Branigan 2005). In support of the indirect influence of emotions, PsyCap is linked to numerous positive personal and organizational outcomes with InfoSec implications, including job performance and satisfaction (Luthans et al. 2007a), low absenteeism (Avey et 
al. 2006), and low turnover and stress (Avey et al. 2009). It is also associated with increased citizenship, decreased deviance (Avey et al. 2011), mastery orientation, and innovation (Luthans et al. 2011). InfoSec researchers have taken an interest in the role of ordinary insiders, including their ability to strengthen their firms' InfoSec (e.g., Albrechtsen \& Hovden 2009; Hsu et al. 2015; Posey et al. 2013). Thus, we posit that PsyCap can be uniquely applied in an InfoSec setting because of its malleability and its focus on the average person (Sheldon \& King 2001), which should facilitate insiders' InfoSec-related work performance.

As a higher-order construct consisting of hope, self-efficacy, resilience, and optimism (Luthans et al. 2007a), PsyCap can be viewed through the lens of resource theory. Hobfoll $(1989,2002)$ stipulated that individuals require resources for functioning and will thus seek available resources and curb unnecessary resource expenditures when possible. As a resource, PsyCap can be built by either microintervention-PsyCap interventions (Luthans et al. 2007b) —or macro-intervention, such as a supportive climate (Luthans et al. 2008b). The ability to build PsyCap is key to human flourishing (Culbertson et al. 2010), and PsyCap comprises state-like rather than trait-like characteristics (Fugate et al. 2012;

Zuckerman 1983). The former are malleable and developable, whereas the latter are innate and inflexible (Chen et al. 2000). Because PsyCap can be manipulated and managed as a resource, it is relevant to InfoSec research and practice (Burns et al. 2017). Table 1 presents formal definitions of each PsyCap component.

Table 1. PsyCap Components

\begin{tabular}{|c|c|}
\hline $\begin{array}{l}\text { PsyCap } \\
\text { Component }\end{array}$ & Definition \\
\hline Self-efficacy & $\begin{array}{l}\text { A role-breadth characteristic defined as an "employee's perceived capability of carrying out a } \\
\text { broader and more proactive set of work tasks that extend beyond prescribed technical } \\
\text { requirements" (Parker 1998, p. 835). }\end{array}$ \\
\hline Hope & $\begin{array}{l}\text { A "positive motivational state that is based on an interactively derived sense of successful (a) } \\
\text { agency (goal-directed energy) and (b) pathways (planning to meet goals)" (Snyder et al. 1991, p. } \\
\text { 287). }\end{array}$ \\
\hline Optimism & $\begin{array}{l}\text { A characteristic of individuals who "expect things to go their way and generally believe that good } \\
\text { rather than bad things will happen to them" (Scheier \& Carver 1985, p. 219). }\end{array}$ \\
\hline Resilience & $\begin{array}{l}\text { "The positive psychological capacity to rebound, to 'bounce back' from adversity, uncertainty, } \\
\text { conflict, failure or even positive change, progress and increased responsibility" (Luthans 2002, p. } \\
702 \text { ). }\end{array}$ \\
\hline
\end{tabular}




\subsubsection{Happiness and PsyCap}

The BBT explains how certain positive emotions build lasting psychological resources such as those conceptualized in PsyCap. Fredrickson (2001) described this building role of positive emotions:

[J]oy can have the incidental effect of building an individual's physical, intellectual, and social skills. Importantly, these new resources are durable and can be drawn on later, long after the instigating experience of joy has subsided (p. 305).

Additional research has demonstrated that experiences of happiness precede individuals' attainment of desirable resources (Lyubomirsky et al. 2005).

Insiders experiencing happiness when considering the protection of their firm against InfoSec threats are satisfied with the current state of response to such threats and believe no further actions are needed. These experiences signal an expectation of positive outcomes related to the organization's protection against threats with no additional individual precaution-taking efforts required. This positive outlook works to build the work-related hope, resilience, optimism, and self-efficacy that comprise insiders' PsyCap. Based on the building role of positive emotions in the BBT, we predict the following: H1a. Happiness will be positively related to PsyCap.

\subsubsection{Interest and PsyCap}

Similarly, experiences of interest should contribute to insiders' positive psychological resources (Fredrickson 2001). Interest implies an expectation of a positive outcome, and this relates directly to the PsyCap components of hope, optimism, resilience, and self-efficacy. Interest also results in increased attention and concentration (Silvia 2008), and it thus relates to a desire to engage with the situation (Smith \& Ellsworth 1985). This tendency toward engagement reflects the approach orientation of interest and other positive emotions (Cacioppo et al. 1999; Carver \& Scheier 1990). As discussed in prior InfoSec research (Burns et al. 2017), insiders' PsyCap is enhanced by development techniques related to the experience of interest. Goal setting, participation, and psychological arousal reflect people's interests and have also been shown to develop insiders' PsyCap (Luthans et al. 2006; Luthans et al. 2008a; Luthans et al. 2007a). Thus,

H2a. Interest will be positively related to PsyCap.3.2.3. Sadness and PsyCap 
Lazarus (1991) noted that "loss undermines our appreciation of life and may lead to withdrawal and depression" (p. 108). In this way, loss emotions can tax psychological resources. Insiders' experience of sadness when considering the protection of their firm from InfoSec threats signals an expectation of negative, uncontrollable consequences. Further, sadness relates to insiders' feelings of personal helplessness in protecting their organizations. In view of the underlying components of PsyCap, sadness and its association with negative, uncontrollable consequences should relate negatively to insiders' workrelated hope, optimism, resilience, and self-efficacy. Thus, we predict the following:

H3a. Sadness will be negatively related to PsyCap.

\subsubsection{Anxiety and PsyCap}

Anxiety is characterized by insiders' "appraisals of facing uncertain existential threats" (Han et al. 2007, p. 160). As a negative emotion, anxiety implies that such uncertainty involves an anticipation of a negative outcome (Beaudry \& Pinsonneault 2010). In the case of negative expectations, perceived outcome uncertainty associated with experiences of anxiety leads individuals to engage in avoidance tendencies (Beaudry \& Pinsonneault 2010; Lazarus 1991). Avoidance can be seen as an adaptive, simplified strategy readily explained by the BBT, because of the narrowing of an individual's thoughtaction repertoire. This narrowed cognition is supported by research showing a negative association between anxiety and spontaneous, creative IT interaction (Beaudry \& Pinsonneault 2010). In contrast to the broadened information processing associated with positive emotions (Fredrickson 2001), anxiety leads to information-limiting (e.g., shielding) strategies (Beaudry \& Pinsonneault 2010). Anxiety and its associated avoidance strategies reflect a lack of confidence in a positive outcome, taxing individuals' PsyCap through a negative relationship with hope, optimism, resilience, and self-efficacy. Thus, H4a. Anxiety will be negatively related to PsyCap.

\subsection{The Impact of PsyCap on Precaution Taking}

Whether PsyCap is viewed as a psychological resource or simply as a psychological state, the previously established links between PsyCap and organizational outcomes provide a basis for the relationship between PsyCap and precaution taking. PsyCap is positively linked to an increase in both job 
performance and satisfaction (Luthans et al. 2007a), as well as increased organizational commitment and citizenship (Avey et al. 2011). The positive impacts of job satisfaction, commitment, and citizenship are closely linked, and these impacts are supported by findings that individuals who are satisfied with their jobs are better organizational citizens and can be expected to perform both in- and extra-role behaviors to support the firm (Bateman \& Organ 1983; Williams \& Anderson 1991). These role-behavior links have also been demonstrated in InfoSec research (Hsu et al. 2015).

Moreover, individual PsyCap components, as role-breadth resources of positive psychological capabilities, relate to precaution taking. Through its influence on positive expectations (Scheier \& Carver 1985), optimism should relate positively to precaution taking by building confidence for successful action. Similarly, resilience should relate positively to precaution taking by buffering the demoralizing effect of past losses and/or failures, thereby enabling insiders to recover from adversity (Luthans 2002). The role-breadth, work-related component of self-efficacy should relate positively to precaution taking, as it pertains to the broad set of security roles insiders assume in fulfilling organizational duties. Hope, which includes both the ability to meet goals and a plan for doing so (Snyder et al. 1991; Snyder et al. 1996), should relate positively to precaution taking by increasing insiders' perception of the likelihood of successfully enacting protective behavior. We thus predict the following:

H5a. PsyCap will be positively related to precaution taking.

\subsection{The Mediated Relationship of Emotions through Psychological Distancing}

Emotions also influence behavior indirectly through psychological distancing. The influence of emotions on psychological distancing in an InfoSec context thus constitutes an important new research avenue.

Threats to the firm's security elicit emotions that influence psychological distancing directly and precaution taking indirectly. Our full model therefore includes the mediating influence of emotions on precaution taking through psychological distancing.

\subsubsection{Happiness and Psychological Distancing}

In the framework of emotions, happiness relates to an expectation of positive outcomes paired with a lack of control over the consequences (Beaudry \& Pinsonneault 2010). Research has shown that 
achievement emotions such as happiness, serenity, and relief are related to behavioral withdrawal because they promote an inward focus (Harlé \& Sanfey 2010). In addition, lack of control over consequences has long been associated with withdrawal from future attempts to act (e.g., Abramson et al. 1978; Carver \& Scheier 1982): Individuals perceiving a lack of control distance themselves psychologically from the situation (Dweck 1975).

In the context of InfoSec, experiencing happiness when considering the protection of their organization signals insiders' satisfaction with the current protection of the organization and does not generate the necessity for individual precaution taking. Happiness relates to an expectation of a positive outcome regarding the organization's protection from InfoSec threats with no additional precaution taking. Happiness also relates to an expectation of an uncontrollable (but positive) outcome. Insiders who experience happiness when considering the protection of their firm could be described as "blissfully ignorant." Such insiders believe that the organization will ultimately be protected even though there is nothing they can actively do to protect its InfoSec. The experience of happiness leads insiders to divert their attention elsewhere, particularly inward. Therefore, based on the lack of control and inward focus accompanying achievement emotions, we hypothesize the following:

H1b. Happiness will be positively related to psychological distancing.

\subsubsection{Interest and Psychological Distancing}

Interest is a high-activation emotion related to activation, concentration, and approach orientation (Silvia 2008). Research has identified a strong desire to "attend to the situation" accompanying experiences of interest (Smith \& Ellsworth 1985, p. 832). The high degree of attention thus accompanying interest conflicts with the preconditions for psychological distancing (Smith \& Ellsworth 1985), while performance avoidance through psychological distancing is linked to low interest (Sansone et al. 2010). Insiders experiencing interest when considering the protection of their organizations expect that positive outcomes are possible but that the result depends upon their actions (i.e., positive outcome expectation with control over consequences). Additionally, the experience of interest in protecting a firm from InfoSec threats is accompanied by a desire to attend to the situation proactively through precaution 
taking. The combination of positive outcome expectation, instrumentality of behavior, and intrinsic motivation accompanying experiences of interest leads us to hypothesize the following:

\section{H2b. Interest will be negatively related to psychological distancing.}

\subsubsection{Sadness and Psychological Distancing}

Sadness is an emotional reaction stimulated by an expectation of a negative outcome over which an individual has no control (Beaudry \& Pinsonneault 2010). As explained in the emotions framework, as a loss emotion, sadness shares a perceived lack of control with achievement emotions such as happiness. Because the lack of control over consequences that is associated with sadness can be linked to helplessness and withdrawal (Abramson et al. 1978; Carver \& Scheier 1982; Dweck 1975), the elicitation of sadness is associated with resignation rather than struggle (Lazarus 1991).

Experiencing sadness at the prospect of protecting an organization from InfoSec threats signals insiders' expectations of negative consequences from these threats that are beyond their control. Such insiders have accepted their organizations' vulnerability to InfoSec threats and see no benefit in taking proactive precautions. Instead of striving for the unattainable, they cope with their lack of agency by diverting their attention from the situation. Given the lack of control and the tendency toward resignation associated with sadness, we predict the following:

H3c. Sadness will be positively related to psychological distancing.

\subsubsection{Anxiety and Psychological Distancing}

Anxiety is a negative emotion that arises from the uncertainty of events paired with situational control (Han et al. 2007). When facing uncertain threats, individuals may seek to reduce emotional instability by avoiding the stressor or diverting attention from it (Beaudry \& Pinsonneault 2010). In the workplace, avoidance is often either physical (e.g., lateness, absenteeism, or quitting) or psychological (e.g., denial, ignoring, refusing to respond) (Keaveney \& Nelson 1993). In terms of adaptation, the avoidance of anxiety-inducing stimuli through psychological distancing reflects the avoidance action tendency associated with negative emotions (Beaudry \& Pinsonneault 2010; Yi \& Baumgartner 2004). Similarly, role-based stressors are linked to employees' psychological withdrawal (Keaveney \& Nelson 
1993). Avoidance emotions are positively linked to psychological distancing and are related to avoidance strategies (e.g., mental disengagement, wishful thinking, and escapism) (Beaudry \& Pinsonneault 2010).

Although the experience of anxiety reflects an expectation of control over the consequences of anxiety-inducing stimuli, it is also linked to insiders' expectations of negative outcomes and narrowed thought-action repertoires. Thus, insiders who experience anxiety when considering the protection of their firms from InfoSec threats expect a negative outcome, leading them to engage in avoidance responses (i.e., psychological distancing). Although this response is physiologically and psychologically adaptive, it is maladaptive in terms of organizational InfoSec. Thus, we hypothesize the following:

\section{H4b. Anxiety will be positively related to psychological distancing.}

\subsection{The Impact of Psychological Distancing on Precaution Taking}

As noted, psychological distancing is a withdrawal mechanism whereby individuals divert their attention from a stressful encounter (Beaudry \& Pinsonneault 2010). Instead of addressing the stimulus directly, an individual engaging in psychological distancing attempts to restore emotional stability by denying, ignoring, or refusing to respond to the situation (Beaudry \& Pinsonneault 2010; Keaveney \& Nelson 1993). Psychological distancing can leave threatening situations unaddressed (Folkman et al. 1986), is linked to maladaptation (Beaudry \& Pinsonneault 2010), and can be negatively related to IT use (Beaudry \& Pinsonneault 2010).

Rather than taking precautions to mitigate threats, insiders who engage in psychological distancing cope with a potentially stressful encounter by ignoring or refusing to respond to the threat (e.g., “time will take care of this threat to my organization's information security") or engaging in denial (e.g., "there is nothing I can do about the threat to my organization's information security"). Therefore,

H5b. Psychological distancing will be negatively related to precaution taking.

\subsection{The Mediating Role of PsyCap and Psychological Distancing}

Finally, the indirect relationships between emotions and precaution taking through PsyCap and psychological distancing provide the potential for important mediating relationships (Beaudry \& Pinsonneault 2010; Luthans et al. 2008b). We are interested in the influence of emotions on insiders' 
InfoSec-related precaution taking. Based on the previously discussed, hypothesized relationships of discrete emotions with PsyCap (e.g., Smith \& Ellsworth 1985; Smith \& Lazarus 1990) and psychological distancing (e.g., Abramson et al. 1978; Beaudry \& Pinsonneault 2010; Carver \& Scheier 1982), and the subsequent hypothesized relationships of precaution taking with PsyCap (e.g., Avey et al. 2011) and psychological distancing (e.g., Keaveney \& Nelson 1993), we formally hypothesize a mediating relationship between emotions and precaution taking through PsyCap and psychological distancing:

H6. PsyCap and psychological distancing will mediate the relationship between emotions and precaution taking.

\section{METHODOLOGY}

\subsection{Data Collection}

We tested our model using a cross-sectional survey research methodology that employs panel data, a well-established approach in InfoSec research (D’Arcy et al. 2014; Lowry et al. 2016). Given the sensitive nature of security responses, anonymity is useful in encouraging candid responses (Kays et al. 2012). Online panels are an established medium for gathering security-related data because they offer true anonymity (not simply confidentiality). This, in turn, encourages candid responses and reduces response bias (Podsakoff et al. 2003). Used properly, panels have several methodological strengths. ${ }^{\mathrm{ii}}$

\subsection{Panel Sample}

To examine our research model, responses were collected from a sample of organizational insiders from a prescreened online panel provider. Initially, we received responses from 597 insiders. After excluding incomplete responses and screening for non-conscientious (e.g., straight-ticket) responding, our final sample was 405 respondents. This figure equates to a usable-to-collected response rate of $67.8 \%$, which meets or exceeds the rate of other similar research (D’Arcy et al. 2014). As recommended, none of the respondents in our retained sample had missing values for more than $5 \%$ of all items, and we employed mean replacement for all missing values (Hair et al. 2014). In terms of power, our large sample size provides an adequate ratio of observations to measurement items (10.66 observations for every measurement item) (Beaudry \& Pinsonneault 2010). 
Our sample was $53.8 \%$ female, while the average age was 44.8 years and the average organizational tenure was 10.6 years. Moreover, $71.0 \%$ of the sample held at least an associate's (twoyear) degree, and 57.9\% held a bachelor's degree. Finally, $13.6 \%$ held an IT position, and 33.1\% worked in managerial roles. As shown in Appendix A, our sample includes respondents working at organizations of all sizes in a variety of industries in the U.S.

\subsection{Measurement}

The survey was developed based on a thorough literature review and is fully detailed in Appendix B. Critical to any study are the validity and reliability of the measures employed (Gefen et al. 2011; Straub 1989). As recommended, the scales included in this study were employed in their previously published forms when possible (Straub et al. 2004). All items included in the final survey received subject-matterexpert review and were pilot tested before execution. Several of our hypotheses asked respondents to report their emotional reactions to acting against security threats to their organization. In line with Beaudry and Pinsonneault (2010), we used Lazarus and Folkman's (1984) emotional intensity ratings to ascertain participants' emotional reactions. ${ }^{\text {iii }}$ PsyCap was measured using items adapted from the questionnaire developed by Luthans et al. (2007b). The original PsyCap questionnaire includes 24 items (six for each of the four first-order components) that have been used successfully in the business literature (e.g., Luthans et al. 2007a; Luthans et al. 2007b). ${ }^{\text {iv }}$ Psychological distancing was measured using a threeitem scale adapted from Beaudry and Pinsonneault (2010). To adapt the psychological distancing measure for our study, we asked respondents to indicate their reaction when confronted with a potential threat to their organization's InfoSec. ${ }^{\mathrm{v}}$ Our construct reflecting insiders' precaution taking was adopted directly from Boss et al. (2009). ${ }^{\mathrm{vi}}$

\section{ANALYSES AND RESULTS}

The research model was analyzed in a two-step procedure (e.g., Gerbing \& Anderson 1988) using Mplus, a covariance-based structural equation modeling (SEM) tool (Muthén \& Muthén 1998-2010). In the first step, we ran a confirmatory factor analysis (CFA) to establish the validity of the measures to be included in the subsequent structural model. Upon confirmation of the research model's validity, we assessed the 
hypothesized research model.

\subsection{Construct Validity}

Following Luthans et al. (2007a), we conceptualized PsyCap as a second-order construct. ${ }^{\text {vii }} \mathrm{We}$ also conducted a CFA of our full measurement model, including the higher-order, reflective PsyCap construct, to assess the validity of our measures. Per Hair et al. (2006), we report the latent variable correlations along with evidence of convergent and discriminant validity. As Table 2 shows, the reflective measures included in the measurement model exhibited appropriate validity (i.e., composite reliabilities were above 0.70, AVEs were above 0.50, and the Fornell-Larcker criterion was met) (Hair et al. 2006; Hair et al.

2014). The measurement model's fit statistics also met or exceeded previously established levels (e.g., Bassellier et al. 2003), including those used in similar studies involving emotions (Beaudry \&

Pinsonneault 2010), with a comparative fit index (CFI) of 0.95 , a root mean square error of approximation (RMSEA) of 0.04 , and a 1.7 ratio of chi-square to degrees of freedom.

Table 2. Measurement Model Statistics

\begin{tabular}{lrlllllll}
\hline Latent Construct & $\mathbf{( 1 )}$ & $\mathbf{( 2 )}$ & $\mathbf{( 3 )}$ & $\mathbf{( 4 )}$ & $\mathbf{( 5 )}$ & $\mathbf{( 6 )}$ & $\mathbf{( 7 )}$ & $\mathbf{C R}^{\mathbf{i i}}$ \\
\hline PsyCap (1) & $\mathbf{0 . 7 2}$ & & & & & & & 0.91 \\
Happiness (2) & 0.29 & $\mathbf{0 . 8 6}$ & & & & & & 0.95 \\
Sadness (3) & -0.14 & 0.01 & $\mathbf{0 . 7 9}$ & & & & & 0.92 \\
Interest (4) & 0.36 & 0.67 & 0.18 & $\mathbf{0 . 6 2}$ & & & & 0.83 \\
Anxiety (5) & -0.18 & 0.05 & 0.68 & 0.36 & $\mathbf{0 . 7 2}$ & & & 0.89 \\
Precaution taking (6) & 0.47 & 0.32 & -0.05 & 0.49 & 0.01 & $\mathbf{0 . 6 0}$ & & 0.82 \\
Psych. distancing (7) & -0.12 & 0.09 & 0.28 & -0.02 & 0.28 & -0.21 & $\mathbf{0 . 5 5}$ & 0.78 \\
\hline
\end{tabular}

Estimator $=$ MLR; chi-square $=1066.111 ;$ d.f. $=640 ;$ MLR scaling correction factor $=1.1591 ; \mathrm{CFI}=0.945$; RMSEA $=0.041 ;{ }^{i}$ AVEs are bolded along diagonal; ${ }^{i i}$ composite reliability

\subsection{Structural Model}

The first ten hypothesized relationships in the research model (H1a-H5b) were tested using SEM. As in the CFA, the chi-square statistic and degrees of freedom $\left(\chi^{2}\right.$ to d.f. ratio $\left.=1.7\right)$, a goodness of fit index $(\mathrm{CFI}=0.940)$, and a badness of fit index $($ RMSEA $=.042)$ indicated that the structural model has good fit overall (Hu \& Bentler 1999; Kline 2010). Table 3 summarizes the results. Seven of our ten hypothesized relationships were empirically supported.

\subsection{Controls}

To establish the structural model's robustness, the analyses were performed again using several controls. 
Table 3. Structural Model Results

\begin{tabular}{lllll}
\hline Hyp. & Hypothesis (direction) & $\begin{array}{l}\text { Path } \\
\text { Coefficient }\end{array}$ & $\begin{array}{l}\boldsymbol{p} \text {-value } \\
\text { (two-tailed) }\end{array}$ & Supported? \\
\hline H1a & Happiness $\rightarrow$ PsyCap $(+)$ & -0.050 & $0.524(\mathrm{n} / \mathrm{s})$ & No \\
H1b & Happiness $\rightarrow$ Psychological distancing $(+)$ & 0.315 & $0.000^{* * *}$ & Yes \\
H2a & Interest $\rightarrow$ PsyCap $(+)$ & 0.549 & $0.000^{* * *}$ & Yes \\
H2b & Interest $\rightarrow$ Psychological distancing $(-)$ & -0.371 & $0.000^{* * *}$ & Yes \\
H3a & Sadness $\rightarrow$ PsyCap (-) & 0.023 & $0.765(\mathrm{n} / \mathrm{s})$ & No \\
H3b & Sadness $\rightarrow$ Psychological distancing $(+)$ & 0.137 & $0.095(\mathrm{n} / \mathrm{s})$ & No \\
H4a & Anxiety $\rightarrow$ PsyCap (-) & -0.385 & $0.000^{* * *}$ & Yes \\
H4b & Anxiety $\rightarrow$ Psychological distancing $(+)$ & 0.300 & $0.002^{* *}$ & Yes \\
H5a & PsyCap $\rightarrow$ Precaution taking $(+)$ & 0.462 & $0.000^{* * *}$ & Yes \\
H5b & Psychological distancing $\rightarrow$ Precaution taking $(-)$ & -0.151 & $0.015^{*}$ & Yes \\
\hline
\end{tabular}

${ }^{*} p \leq 0.05 ; * * p \leq 0.01 ; * * * p \leq 0.001 ; \mathrm{n} / \mathrm{s}=$ not significant; estimator $=$ MLR;

MLR scaling correction factor $=1.1595 ;$ chi-square $=1104.433 ;$ d.f. $=645 ;$ CFI $=0.940 ;$ RMSEA $=0.042$

As shown in Figure 4, we included controls for age, gender, organizational tenure, and whether the insider had an IT or a managerial position. Because our construct of precaution taking is a self-reported measure of positive behavior, we also controlled for social desirability bias. ${ }^{\text {viii }}$ We also included controls for more general positive and negative affect using the shortened Positive and Negative Affect Schedule (PANAS) (Mackinnon et al. 1999; Watson et al. 1988). ${ }^{\text {ix }}$

\section{Figure 4. Structural Model Results Including Controls}

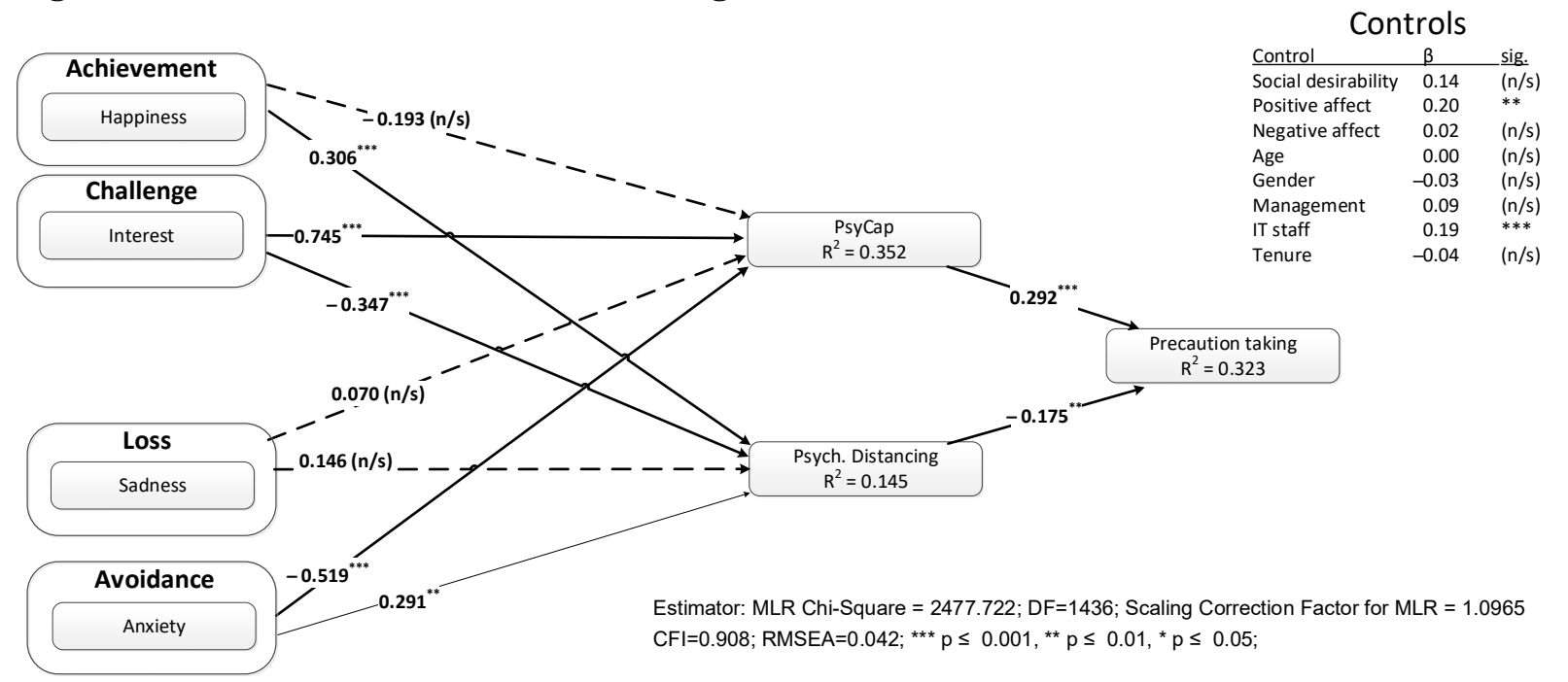

Apart from IT staff and positive affect, all controls were insignificant in the model (see Figure 4).

The significance and direction of all substantive variables remained consistent when controlling for multiple insider characteristics. We also conducted a formal test for common method variance (CMV) that detected no bias from CMV (Appendix C). 


\subsection{Mediation Test}

To examine H6, we performed a bootstrapping analysis as recommended by MacKinnon et al. (2004) and Vance et al. (2015). As in previous research (e.g., Burns et al. 2017), using Mplus' model indirect procedure, we constructed bias-controlled confidence intervals from 5,000 resamples. ${ }^{\mathrm{x}}$ Table 4 summarizes the results of the formal tests of the mediated effects of emotion on precaution taking.

\section{Table 4. Bootstrapped CI Tests for Mediation}

\section{Tested Mediation Relationship}

\begin{tabular}{llllll}
\multicolumn{3}{c}{ Mediation Test (ab) } & \multicolumn{3}{c}{ Full/Partial Mediation } \\
Test (c') & \\
$2.5 \%$ & $97.5 \%$ & Mediation? & $\begin{array}{l}2.5 \% \\
\text { lower }\end{array}$ & $\begin{array}{c}97.5 \% \\
\text { upper }\end{array}$ & Full or \\
lower & upper & & $\begin{array}{l}\text { lortial? } \\
\text { bound }^{\mathrm{i}}\end{array}$ & bound $^{\mathrm{i}}$ & \\
bound $^{\mathrm{i}}$ & bound $^{\mathrm{i}}$ & & & &
\end{tabular}

PsyCap Mediation

H6a: Happiness $\rightarrow$ PsyCap $\rightarrow$ Precaution taking

H6b: Interest $\rightarrow$ PsyCap $\rightarrow$ Precaution taking

H6c: Sadness $\rightarrow$ PsyCap $\rightarrow$ Precaution taking

H6d: Anxiety $\rightarrow$ PsyCap $\rightarrow$ Precaution taking

Psychological Distancing Mediation

H6e: Happiness $\rightarrow$ PD $\rightarrow$ Precaution taking

H6f: Interest $\rightarrow$ PD $\rightarrow$ Precaution taking

H6g: Sadness $\rightarrow$ PD $\rightarrow$ Precaution taking

H6h: Anxiety $\rightarrow$ PD $\rightarrow$ Precaution taking

Estimator $=\mathrm{ML} ;$ resamples $=5,000 ;$ ibias-controlled confidence intervals; ch

$\begin{array}{rrlrrl}-0.072 & 0.029 & \text { No } & -0.202 & 0.130 & \mathrm{n} / \mathrm{a} \\ 0.075 & 0.273 & \text { Yes } & 0.173 & 0.660 & \text { Partial } \\ -0.039 & 0.061 & \text { No } & -0.133 & 0.126 & \mathrm{n} / \mathrm{a} \\ -0.215 & -0.053 & \text { Yes } & -0.223 & 0.143 & \text { Full } \\ & & & & & \\ -0.109 & -0.010 & \text { Yes } & -0.202 & 0.130 & \text { Full } \\ 0.012 & 0.125 & \text { Yes } & 0.173 & 0.660 & \text { Partial } \\ -0.066 & 0.001 & \text { No } & -0.133 & 0.126 & \mathrm{n} / \mathrm{a} \\ -0.107 & -0.008 & \text { Yes } & -0.223 & 0.143 & \text { Full }\end{array}$

$\mathrm{CFI}=0.940 ; \mathrm{RMSEA}=0.048 \mathrm{PD}=$ psychological distancing

\section{DISCUSSION}

Researchers and practitioners have largely agreed that organizational insiders greatly influence organizational InfoSec through their positive and negative behaviors. In the contemporary firm, taking precautions against security threats requires behavioral adaptation. These encounters often elicit various emotions, each with its own motivational influence (Lazarus 1991). Previous research affirms that individuals' reactions to InfoSec demands in the workplace can be explained, at least in part, by their emotion-focused coping mechanisms (Boss et al. 2015; D’Arcy et al. 2014). However, previous studies have not yet uncovered the influence of the disparate emotions elicited in adaptational encounters that require the insider to take precautions against security threats.

To address this gap, we assessed the mediated influence of four disparate emotions across the four quadrants of the previously published framework of emotions (i.e., Beaudry \& Pinsonneault 2010) on precaution taking. Our results provide support for the unique role of distinct positive and negative 
emotions in insiders' precaution taking, working through psychological distancing and the important psychological resources of PsyCap.

A primary goal of our study is to establish the mediating role of PsyCap mechanisms and psychological distancing. Prior to this assessment, however, we needed to examine the possible direct relationships between these potential mediators and insiders' precaution taking. Supporting our contentions, we found that insiders' PsyCap is positively linked to precaution taking and that psychological distancing is negatively associated with precaution taking. Aside from consisting of proorganizational and often extra-role behaviors, the positive relationship between PsyCap and precaution taking adds to the myriad positive organizational outcomes attributable to PsyCap. It also highlights the importance of introducing the concepts of positive psychology into the study of insiders' beneficial security-related behaviors. In addition, our finding that psychological distancing negatively influences precaution taking supports our contention that such distancing can be a maladaptive response to InfoSec threats.

For our mediation assessments, we examined the influence of emotions through insiders' PsyCap and found two important mediating relationships: (1) Interest is partially mediated by PsyCap, and (2) Anxiety is fully mediated by insiders' psychological distancing. The significant positive relationship between interest and PsyCap supports the "build" hypothesis of the BBT, which explains that experiences of positive emotions can build lasting psychological resources (Fredrickson \& Branigan 2005). Further, according to the framework of emotions, interest is a challenge emotion and is associated with a strong desire to take action. In support of interest's role as a high-activation emotion, our mediation analysis found that it is directly related to precaution taking, resulting in partial mediation.

Conversely, anxiety is fully mediated by PsyCap. The negative relationship between anxiety and PsyCap reflects the taxing role of negative emotions on positive psychological resources implied by the BBT (Fredrickson \& Branigan 2005). In our mediation analyses, anxiety is not directly related to precaution taking but is indirectly related through insiders' PsyCap. In this way, PsyCap suppresses the impact of insiders' experience of anxiety: Although anxiety negatively affects PsyCap, PsyCap is 
positively related to precaution taking. This makes theoretical sense, as PsyCap contains powerful positive psychological resources that mitigate the negative motivational impact associated with the experience of negative emotions such as anxiety. Notably, the two emotions that are "low activation" and are associated with a lack of control—happiness (an achievement emotion) and sadness (a loss emotion) — were not mediated by PsyCap. These findings point to the importance of challenge and avoidance emotions in driving precaution taking through insiders' PsyCap.

Second, we examined the influence of emotions through insiders' psychological distancing and found three additional mediating relationships: (1) Happiness is fully mediated by psychological distancing, (2) Interest is partially mediated by psychological distancing, and (3) Anxiety is fully mediated by psychological distancing. Because happiness is classified as a low-activation emotion, we hypothesized that it would be mediated by psychological distancing. Our analyses support full mediation, with a positive relationship between happiness and psychological distancing as well as between psychological distancing and precaution taking. Conversely, interest is classified as a high-activation emotion and was hypothesized to be negatively related to psychological distancing. Thus, psychological distancing provides what is termed inconsistent mediation between interest and precaution taking (Kenny 2018), with interest relating negatively to psychological distancing and psychological distancing relating negatively to precaution taking. Finally, psychological distancing fully mediates anxiety in our model. That is, anxiety is positively related to psychological distancing but has no direct relationship with precaution taking. This finding is in line with our hypothesis that experiences of anxiety can lead to maladaptive avoidance responses such as psychological distancing.

As with PsyCap, sadness was also not mediated by psychological distancing. Because psychological distancing requires insiders' effort, the low activation of sadness might not elicit the sufficient exertion required of psychological distancing. Sadness, as a loss emotion, signals a belief that a loss has already occurred. Therefore, because precaution taking reflects behavior aimed at preventing loss, the potential influence of sadness on precaution taking is likely limited. In fact, sadness is the only emotion that exhibited no significant relationship in our research model. Our model is also robust for 
multiple controls, including the stable personality characteristics of positive and negative affect.

\subsection{Implications and Contributions}

This study makes several compelling contributions to InfoSec research and practice and thus opens new avenues of research, theory, and application. Our research model provides new insights into the central role of emotions in insiders' precaution taking and answers the call for a broadened theoretical repertoire in IS (Abraham et al. 2013) and, specifically, in behavioral InfoSec research (Crossler et al. 2013; Willison \& Warkentin 2013). Principally, the results illuminate the diverse, mediated influences of emotions on insiders' precaution taking. Although InfoSec scholars have become increasingly interested in the adaptive influence of emotions on insiders' security-related behavior (e.g., D'Arcy et al. 2014), they have yet to simultaneously examine the role of discrete positive and negative emotions across the recently established framework of emotions in IS. Extending the work of Beaudry and Pinsonneault (2010), we were able to integrate positive and negative emotions into the same research model. This is important because adaptational encounters often elicit emotions across the emotional framework simultaneously (Lazarus 1991; Lazarus \& Folkman 1984). Therefore, studying disparate emotions in the same research model provides a more complete picture of the role of emotions in driving behavior. In addition, our model allows for formal mediation testing of key psychological mechanisms for all emotions included in the study, both positive and negative.

Our study underscores the complex relationships among emotions and behavioral adaptations. Discrete emotions are uniquely linked to evolutionarily adaptive responses (Nesse \& Ellsworth 2009). Therefore, as adaptive intermediaries between stimulus and behavior (Lazarus 1991), emotions are of paramount importance to InfoSec. This is so because insiders' emotional responses to security-related stimuli influence their precaution taking and ignoring the influence of emotion may undermine organizational security efforts. For example, if security training creates anxiety for insiders by focusing excessively on the noxiousness of threats, insiders' precaution taking may be negatively influenced by the positive relationship between anxiety and psychological distancing.

Our findings indicate that the emotions framework is useful for untangling the complex 
influences of discrete emotions. The challenge emotion of interest is the only emotion whose relationship with precaution taking is partially mediated by both PsyCap and psychological distancing. This finding demonstrates that interest is the only emotion in our study directly related to precaution taking and significantly related to both mediators. The key role of interest in motivating insiders' precaution taking reflects the growing realization that experiences of interest are fundamental to intrinsic motivation (Sansone \& Thoman 2005; Sansone et al. 2010). This insight into interest's role in motivating insiders' precaution taking is novel for InfoSec. Although previous studies have examined attitudes such as apathy (Boss et al. 2009) and rationalization techniques such as neutralizations (Siponen \& Vance 2010) to explain security-related behaviors, relatively little research has sought to uncover the motivational influence of emotional experiences such as that of interest in closing the knowing-doing gap of precaution-taking behaviors (Workman et al. 2008). Non-InfoSec studies have increasingly focused on the powerful influence of intrinsic motivations in system use (Lowry et al. 2015a; Lowry et al. 2013a). We provide evidence of its potentially powerful effects in motivating precaution-taking behaviors in organizational environments.

We found significant relationships between positive emotions and psychological distancing. As an example, we found that interest negatively relates to psychological distancing. Because psychological distancing from information security behavior relates negatively with precaution taking, establishing antecedents that reduce this phenomenon are important for InfoSec research. It is noteworthy that the positive emotions exhibited a stronger relationship (in terms of beta coefficients) with psychological distancing than the negative emotions (i.e., anxiety and sadness).

These findings provide researchers and practitioners with an alternative approach to that currently employed in InfoSec research, which focuses almost exclusively on negative emotions (i.e., fear appeals) as motivators (e.g., Boss et al. 2015; Johnston \& Warkentin 2010). The research model elucidates the role of discrete emotions with respect to their specific action tendencies. Although the action tendencies related to emotion are often considered innate, the elicitation of emotion can be manipulated through conditioning and even organizational interventions (e.g., training). Moreover, emotional stimuli result 
from adaptational encounters (Lazarus 1991). This study ascertained insiders' emotional reactions to protecting their firm from security threats rather than their responses to the threats themselves. This distinction is important, as it is appropriate to measure emotion in response to an encounter rather than to an object (Zhang 2013).

Whereas firms and researchers recognize the importance of emotional reactions, our study shows that the referent of the emotion is pivotal. The security benefit provided by some emotional appeals may be confounded or diminished if emotions are elicited in response to protecting the firm instead of in response to the threat itself. This finding should assist managers with selection and training initiatives. For example, individuals who view protection of their firm as a challenge (i.e., experience challenge emotions such as interest) may be uniquely suited for InfoSec roles that are charged with confronting diverse threats. Additionally, organizational education and training initiatives can influence employees' emotions. As noted above, many employees now see InfoSec as their responsibility but also feel unsure about their personal knowledge and their ability to take adequate precautions (Dell 2017). We contend that this situation can lead to maladaptive emotions such as anxiety in adaptational encounters. Thus, training and education programs that focus not only on threats but also on what can and should be done to prepare for them can help reduce negative emotions and encourage positive emotions.

Understanding the psychological mechanisms through which emotions ultimately affect insiders' precaution taking provides a novel explanation for how emotions lead to changes in such behaviors. To ensure the security of organizational information, it is more important than ever that insiders be psychologically engaged in the InfoSec process. Understanding the emotional precursors of psychological distancing contains great promise for minimizing the aforementioned InfoSec knowing-doing gap. Moreover, our study shows that PsyCap also leads to increased precaution taking. Practitioners can leverage this finding to increase InfoSec through investments in insiders' PsyCap (Burns et al. 2017). We found that PsyCap is enhanced by experiences of interest and weakened by experiences of anxiety. This finding exemplifies the significant role that positive emotions can play in increasing a firm's security.

Finally, we controlled for the more stable characteristics of positive and negative affect. The 
inclusion of the two PANAS constructs controlled for the effect of individuals' general (i.e., lingering) emotions (Forgas \& George 2001; Fredrickson 2001; Kaplan et al. 2009). This is important because general affect is not readily manipulated by organizational stimuli. Unlike discrete emotions, general affect is not the result of specific stimuli but rather is a measure of the general experience of an individual's emotions. Controlling for insiders' general affect demonstrates the importance of manipulating emotional responses to security-related stimuli rather than focusing solely on screening employees for their general affect at the moment of hiring. This finding is particularly relevant for practice, as general affect is much more difficult to change than discrete emotions.

\subsection{Limitations and Future Research}

There are inherent limitations in self-reported InfoSec research. In the absence of observational data regarding actual security behaviors, collecting truly anonymous panel data helped to overcome these limitations, as anonymity fosters uninhibited responses with less susceptibility to social desirability bias than information reported only with confidentiality. The present study determined the influence of discrete emotions on self-reported precaution taking at cross-sectional levels of organizational insiders. However, our inability to capture emotional responses from insiders in a controlled, experimental setting is an additional limitation. To compensate for this limitation, and due in part to the difficulty of recalling past emotions, we eliminated temporal disparity between the experience and the survey response by asking insiders to respond with how they feel when they think about protecting their firms from security threats. A potential way to address this limitation in future research would be to conduct a similar study that is longitudinal and conducted at discrete time points.

To overcome the limitations associated with self-reported data, it may be appropriate to employ some form of eye tracking (e.g., Twyman et al. 2014) or a similar neuroscience technique such as functional magnetic resonance imaging (fMRI) (e.g., Warkentin et al. 2016) to observe employees' emotions or triangulate these observations with self-reported data. The key limitation here, however, is that fMRI studies are highly artificial and invasive. To this end, Hibbeln et al. (2016) recently demonstrated that the elicitation of negative emotion can be tracked through mouse movements during 
website use. Other less invasive options, such as facial recognition and keystroke analysis, might also prove effective alternatives. However, such approaches in the workplace raise privacy and ethical issues that must be resolved before introducing them into practice.

These limitations can be addressed in future studies, and our research suggests several additional avenues for future InfoSec research. First, the results support the expansion of the theoretical repertoire to include adaptive underpinnings to precaution taking such as the BBT. Second, the results highlight the need for future research on the impact of positive emotions in InfoSec and the broader IS field. Third, given the tremendous influence of positive and negative emotions, researchers and practitioners must address organizational interventions that can effectively and ethically elicit insiders' positive emotions and avoid stimulating certain negative emotions in the workplace. Given the results of our study, it seems especially important to pique insiders' interest in dealing with InfoSec threats. The types of initiatives that would work best to induce positive emotions and reduce negative emotions elicited in an InfoSec organizational context remain largely unknown. This study highlights the need for future research on the discrete emotions that influence security. Each of the emotions classified by the emotions framework exerts a unique influence. Our research examines a global measure for insiders' precaution taking; therefore, future research can fully examine insiders' emotional responses to specific security-related adaptational encounters in the workplace.

\section{REFERENCES}

Abraham C, Boudreau MC, Junglas I, Watson R (2013) Enriching our theoretical repertoire: the role of evolutionary psychology in technology acceptance. European Journal of Information Systems 22(1):56-75.

Abramson LY, Seligman ME, Teasdale JD (1978) Learned helplessness in humans: Critique and reformulation. Journal of Abnormal Psychology 87(1):49-74.

Albrechtsen E, Hovden J (2009) The information security digital divide between information security managers and users. Computers \& Security 28(6):476-490.

Amabile TM, Barsade SG, Mueller JS, Staw BM (2005) Affect and creativity at work. Administrative Science Quarterly 50(3):367-403.

Avey JB, Luthans F, Jensen SM (2009) Psychological capital: A positive resource for combating employee stress and turnover. Human Resource Management 48(5):677-693.

Avey JB, Patera JL, West BJ (2006) The implications of positive psychological capital on employee absenteeism. Journal of Leadership \& Organizational Studies 13(2):42-60. 
Avey JB, Reichard RJ, Luthans F, Mhatre KH (2011) Meta analysis of the impact of positive psychological capital on employee attitudes, behaviors, and performance. Human Resource Development Quarterly 22(2):127-152.

Bagozzi RP, Gopinath M, Nyer PU (1999) The role of emotions in marketing. Journal of the Academy of Marketing Science 27(2):184-206.

Baskerville R, Spagnoletti P, Kim J (2014) Incident-centered information security: Managing a strategic balance between prevention and response. Information \& Management 51(1):138-151.

Bassellier G, Benbasat I, Reich BH (2003) The influence of business managers' IT competence on championing IT. Information Systems Research 14(4):317-336.

Bateman TS, Organ DW (1983) Job satisfaction and the good soldier: The relationship between affect and employee "citizenship". Academy of Management Journal 26(4):587-595.

Beaudry A, Pinsonneault A (2005) Understanding user responses to information technology: A coping model of user adaptation. MIS Quarterly 29(3):493-524.

Beaudry A, Pinsonneault A (2010) The other side of acceptance: Studying the direct and indirect effects of emotions on information technology use. MIS Quarterly 34(4):689-710.

Bennett RJ, Robinson SL (2000) Development of a measure of workplace deviance. Journal of Applied Psychology 85(3):349-360.

Bennett RJ, Robinson SL (2003) The past, present, and future of workplace deviance research. J Greenberg, ed. Organizational Behavior: The State of the Science (2nd ed.) (Lawrence Erlbaum Associates, Mahwah, NJ) 247-281.

Boss SR, Galletta DF, Lowry PB, Moody GD, Polak P (2015) What do users have to fear? Using fear appeals to engender threats and fear that motivate protective behaviors in users. MIS Quarterly 39(4):837-864.

Boss SR, Kirsch LJ, Angermeier I, Shingler RA, Boss RW (2009) If someone is watching, I'll do what I'm asked: Mandatoriness, control, and information security. European Journal of Information Systems 18(2):151-164.

Burns AJ, Posey C, Roberts TL, Benjamin Lowry P (2017) Examining the relationship of organizational insiders' psychological capital with information security threat and coping appraisals. Computers in Human Behavior 68(March):190-209.

Cacioppo JT, Gardner WL, Berntson GG (1999) The affect system has parallel and integrative processing components: Form follows function. Journal of Personality and Social Psychology 76(5):839-855.

Cambridge Dictionary (n.d.) Precaution. Available at https://dictionary.cambridge.org/us/dictionary/english/precaution (accessed May 17, 2018).

Carver CS, Scheier MF (1982) Control theory: A useful conceptual framework for personality-social, clinical, and health psychology. Psychological Bulletin 92(1):111-135.

Carver CS, Scheier MF (1990) Origins and functions of positive and negative affect: A control-process view. Psychological Review 97(1):19-35.

Cenfetelli RT (2004) Getting in touch with our feelings towards technology. Academy of Management Annual Conference (Academy of Management, New Orleans) F1-F6.

Chen G, Gully SM, Whiteman J-A, Kilcullen RN (2000) Examination of relationships among trait-like individual differences, state-like individual differences, and learning performance. Journal of Applied Psychology 85(6):835-847.

Chen Y, Ramamurthy K, Wen K-W (2012) Organizations' information security policy compliance: Stick or carrot approach? Journal of Management Information Systems 29(3):157-188.

Compeau DR, Higgins CA (1995) Computer self-efficacy: Development of a measure and initial test. MIS Quarterly 19(2):189-211.

Cosmides L, Tooby J (2000) Evolutionary psychology and the emotions. M Lewis, JM Haviland-Jones, eds. Handbook of Emotions, 2nd Edition (Guilford, New York, New York) 91-115.

Crossler RE, Johnston AC, Lowry PB, Hu Q, Warkentin M, Baskerville R (2013) Future directions for behavioral information security research. Computers \& Security 32(2013):90-101. 
Culbertson SS, Fullagar CJ, Mills MJ (2010) Feeling good and doing great: The relationship between psychological capital and well-being. Journal of Occupational Health Psychology 15(4):421-433.

D'Arcy J, Herath T (2011) A review and analysis of deterrence theory in the IS security literature: Making sense of the disparate findings. European Journal of Information Systems 20(6):643-658.

D'Arcy J, Herath T, Shoss M (2014) Understanding employee responses to stressful information security requirements: A coping perspective. Journal of Management Information Systems 31(2):285-318.

Dell (2017) Dell end-user security survey. Available at https://datasecurity.dell.com/wpcontent/uploads/2017/09/Dell-End-User-Security-Survey-2017.pdf (accessed 09-February-2018).

Dlamini M, Eloff JH, Eloff MM (2009) Information security: The moving target. Computers \& Security 28(3):189-198.

Dweck CS (1975) The role of expectations and attributions in the alleviation of learned helplessness. Journal of Personality and Social Psychology 31(4):674-685.

Éthier J, Hadaya P, Talbot J, Cadieux J (2006) B2C web site quality and emotions during online shopping episodes: An empirical study. Information \& Management 43(5):627-639.

Folkman S, Lazarus RS, Dunkel-Schetter C, DeLongis A, Gruen RJ (1986) Dynamics of a stressful encounter: Cognitive appraisal, coping, and encounter outcomes. Journal of Personality and Social Psychology 50(5):992-1003.

Forgas JP, George JM (2001) Affective influences on judgments and behavior in organizations: An information processing perspective. Organizational Behavior and Human Decision Processes 86(1):3-34.

Fredrickson BL (1998) What good are positive emotions? Review of General Psychology 2(3):300-319.

Fredrickson BL (2001) The role of positive emotions in positive psychology: The broaden-and-build theory of positive emotions. American Psychologist 56(3):218-226.

Fredrickson BL (2004) The broaden-and-build theory of positive emotions. Philosophical Transactions Royal Society of London Series B Biological Sciences 359(1449):1367-1378.

Fredrickson BL, Branigan C (2005) Positive emotions broaden the scope of attention and thought-action repertoires. Cognition \& Emotion 19(3):313-332.

Fredrickson BL, Joiner T (2002) Positive emotions trigger upward spirals toward emotional well-being. Psychological Science 13(2):172-175.

Fredrickson BL, Tugade MM, Waugh CE, Larkin GR (2003) What good are positive emotions in crises? A prospective study of resilience and emotions following the terrorist attacks on the United States on September 11th, 2001. Journal of Personality and Social Psychology 84(2):365-376.

Frijda NH (1988) The laws of emotion. American Psychologist 43(5):349-358.

Fritz C, Sonnentag S, Spector PE, McInroe JA (2010) The weekend matters: Relationships between stress recovery and affective experiences. Journal of Organizational Behavior 31(8):1137-1162.

Fugate M, Prussia GE, Kinicki AJ (2012) Managing employee withdrawal during organizational change: The role of threat appraisal. Journal of Management 38(3):890-914.

Gable SL, Haidt J (2005) What (and why) is positive psychology? Review of General Psychology 9(2):103-110.

Gefen D, Straub DW, Rigdon EE (2011) An update and extension to SEM guidelines for admnistrative and social science research. MIS Quarterly 35(2):iii-xiv.

Gerbing DW, Anderson JC (1988) An updated paradigm for scale development incorporating unidimensionality and its assessment. Journal of Marketing Research 25(2):186-192.

Gimeno J, Folta TB, Cooper AC, Woo CY (1997) Survival of the fittest? Entrepreneurial human capital and the persistence of underperforming firms. Administrative Science Quarterly 42(4):750-783.

Haghighat R (2007) The development of the brief social desirability scale (BSDS). Europe's

Journal of Psychology 3, http://dx.doi.org/10.5964/ejop.v5963i5964.5417.

Hair J, Black W, Babin B, Anderson R, Tatham R (2006) Multivariate Data Analysis (6th Edition), (Pearson Education, Upper Saddle River, NJ).

Hair JF, Hult GTM, Ringle CM, Sarstedt M (2014) A Primer on Partial Least Squares Structural Equations Modeling (PLS-SEM), (Sage, Los Angeles, CA). 
Hamill JT, Deckro RF, Kloeber JM (2005) Evaluating information assurance strategies. Decision Support Systems 39(3):463-484.

Han S, Lerner JS, Keltner D (2007) Feelings and consumer decision making: The appraisal-tendency framework. Journal of Consumer Psychology 17(3):158-168.

Hantula DA, Kock N, D’Arcy JP, DeRosa DM (2011) Media Compensation Theory: A Darwinian Perspective on Adaptation to Electronic Communication and Collaboration. G Saad, ed. Evolutionary Psychology in the Business Sciences (Springer, Berlin) 339-363.

Harlé KM, Sanfey AG (2010) Effects of approach and withdrawal motivation on interactive economic decisions. Cognition and Emotion 24(8):1456-1465.

Hibbeln M, Jenkins JL, Schneider C, Valacich JS, Weinmann M (2016) Inferring negative emotion from mouse cursor movements. MIS Quarterly forthcoming.

Hobfoll SE (1989) Conservation of resources: A new attempt at conceptualizing stress. American Psychologist 44(3):513-524.

Hobfoll SE (2002) Social and psychological resources and adaptation. Review of General Psychology 6(4):307-324.

Hsu JS-C, Shih S-P, Hung YW, Lowry PB (2015) The role of extra-role behaviors and social controls in information security policy effectiveness. Information Systems Research 26(2):282-300.

$\mathrm{Hu}$ L, Bentler PM (1999) Cutoff criteria for fit indexes in covariance structure analysis: Conventional criteria versus new alternatives. Structural Equation Modeling: A Multidisciplinary Journal 6(1):155.

Hwang Y (2005) Investigating enterprise systems adoption: uncertainty avoidance, intrinsic motivation, and the technology acceptance model. European journal of information systems 14(2):150-161.

Isen AM (1999) Positive affect. T Dalgleish, MJ Power, eds. Handbook of Cognition and Emotion (John Wiley and Sons, New York, NY) 521-539.

Izard CE (1977) Human emotions, (Springer, New York, New York).

Jarvis CB, MacKenzie SB, Podsakoff PM (2003) A critical review of construct indicators and measurement model misspecification in marketing and consumer research. Journal of Consumer Research 30(2):199-218.

Jarvis CB, MacKenzie SB, Podsakoff PM (2012) The negative consequences of measurement model misspecification: a response to Aguirre-Urreta and Marakas. MIS Quarterly 36(1):139-146.

Johnston AC, Warkentin M (2010) Fear appeals and information security behaviors: An empirical study. MIS Quarterly 34(3):549-566.

Kaplan S, Bradley JC, Luchman JN, Haynes D (2009) On the role of positive and negative affectivity in job performance: a meta-analytic investigation. Journal of Applied Psychology 94(1):162-176.

Kays K, Gathercoal K, Buhrow W (2012) Does survey format influence self-disclosure on sensitive question items? Computers in Human Behavior 28(1):251-256.

Keaveney SM, Nelson JE (1993) Coping with organizational role stress: Intrinsic motivational orientation, perceived role benefits, and psychological withdrawal. Journal of the Academy of Marketing Science 21(2):113-124.

Kenny DA (2018) Mediation. Available at http://davidakenny.net/cm/mediate.htm (accessed February 14, 2018).

Kline RB (2010) Principles and Practice of Structural Equation Modeling, (Guilford press, New York, NY).

Kock N (2009) Information systems theorizing based on evolutionary psychology: an interdisciplinary review and theory integration framework. MIS Quarterly 33(2):395-418.

Lazarus RS (1991) Emotion and adaptation (Kindle Edition), (Oxford University Press, New York, NY).

Lazarus RS, Folkman S (1984) Stress, Appraisal, and Coping, (Springer, New York, NY).

Lee S, Lang A (2009) Discrete emotion and motivation: Relative activation in the appetitive and aversive motivational systems as a function of anger, sadness, fear, and joy during televised information campaigns. Media Psychology 12(2):148-170. 
Liang H, Xue Y (2009) Avoidance of information technology threats: A theoretical perspective. MIS Quarterly 33(1):71-90.

Lowry PB, D’Arcy J, Hammer B, Moody GD (2016) "Cargo Cult" science in traditional organization and information systems survey research: A case for using nontraditional methods of data collection, including Mechanical Turk and online panels. The Journal of Strategic Information Systems 25(3):232-240.

Lowry PB, Gaskin JE, Moody GD (2015a) Proposing the multimotive information systems continuance model (MISC) to better explain end-user system evaluations and continuance intentions. Journal of the Association for Information Systems 16(17):515-579.

Lowry PB, Gaskin JE, Twyman NW, Hammer B, Roberts TL (2013a) Taking 'fun and games' seriously: Proposing the hedonic-motivation system adoption model (HMSAM). Journal of the Association for Information Systems 14(11):617-671.

Lowry PB, Moody GD (2015) Proposing the control-reactance compliance model (CRCM) to explain opposing motivations to comply with organizational information security policies. Information Systems Journal 25(5):433-463.

Lowry PB, Moody GD, Galletta DF, Vance A (2013b) The drivers in the use of online whistle-blowing reporting systems. Journal of Management Information Systems 30(1):153-189.

Lowry PB, Posey C, Bennett RJ, Roberts TL (2015b) Leveraging fairness and reactance theories to deter reactive computer abuse following enhanced organisational information security policies: An empirical study of the influence of counterfactual reasoning and organisational trust. Information Systems Journal 25(3):193-230.

Lowry PB, Schuetzler RM, Giboney JS, Gregory TA (2015c) Is trust always better than distrust? The potential value of distrust in newer virtual teams engaged in short-term decision making. Group Decision and Negotiation 24(4):723-752.

Luthans F (2002) The need for and meaning of positive organizational behavior. Journal of Organizational Behavior 23(6):695-706.

Luthans F, Avey JB, Avolio BJ, Norman SM, Combs GM (2006) Psychological capital development: Toward a micro-intervention. Journal of Organizational Behavior 27(3):387-393.

Luthans F, Avey JB, Patera JL (2008a) Experimental analysis of a web-based training intervention to develop positive psychological capital. Academy of Management Learning \& Education 7(2):209221.

Luthans F, Avolio BJ, Avey JB, Norman SM (2007a) Positive psychological capital: Measurement and relationship with performance and satisfaction. Personnel Psychology 60(3):541-572.

Luthans F, Norman SM, Avolio BJ, Avey JB (2008b) The mediating role of psychological capital in the supportive organizational climate-employee performance relationship. Journal of Organizational Behavior 29(2):219-238.

Luthans F, Youssef CM, Avolio BJ (2007b) Psychological Capital: Developing the Human Competitive Edge (Kindle Edition), (Oxford University Press, New York, NY).

Luthans F, Youssef CM, Rawski SL (2011) A tale of two paradigms: The impact of psychological capital and reinforcing feedback on problem solving and innovation. Journal of Organizational Behavior Management 31(4):333-350.

Lyubomirsky S, King L, Diener E (2005) The benefits of frequent positive affect: does happiness lead to success? Psychological Bulletin 131(6):803-855.

Mackinnon A, Jorm AF, Christensen H, Korten AE, Jacomb PA, Rodgers B (1999) A short form of the Positive and Negative Affect Schedule: Evaluation of factorial validity and invariance across demographic variables in a community sample. Personality and Individual Differences 27(3):405416.

MacKinnon DP (2008) Introduction to Statistical Mediation Analysis, (Erlbaum, New York, NY).

MacKinnon DP, Lockwood CM, Williams J (2004) Confidence Limits for the Indirect Effect: Distribution of the Product and Resampling Methods. Multivariate behavioral research 39(1):99-99. 
Merriam-Webster (n.d.) Precaution. Available at https://www.merriamwebster.com/dictionary/precaution (accessed May 17, 2018).

Moody GD, Galletta DF, Lowry PB (2014) When trust and distrust collide: The engendering and role of ambivalence in online consumer behavior. Electronic Commerce Research and Applications 13(4):266-282.

Muthén L, Muthén B (1998-2010) Mplus User's Guide, Sixth Edition ed.(Muthén \& Muthén, Los Angeles, CA).

Nabi R (2002) Anger, fear, uncertainty, and attitudes: A test of the cognitive-functional model. Communication Monographs 69(3):204-216.

Nesse RM, Ellsworth PC (2009) Evolution, emotions, and emotional disorders. American Psychologist 64(2):129-139.

Öhman A, Mineka S (2001) Fears, phobias, and preparedness: toward an evolved module of fear and fear learning. Psychological Review 108(3):483-522.

Parker SK (1998) Enhancing role breadth self-efficacy: the roles of job enrichment and other organizational interventions. Journal of Applied Psychology 83(6):835-852.

Podsakoff PM, MacKenzie SB, Lee JY, Podsakoff NP (2003) Common method biases in behavioral research: a critical review of the literature and recommended remedies. Journal of Applied Psychology 88(5):879-903.

Posey C, Roberts TL, Lowry PB, Bennett RJ, Courtney JF (2013) Insiders' protection of organizational information assets: Development of a systematics-based taxonomy and theory of diversity for protection-motivated behaviors. MIS Quarterly 37(4):1189-1210.

Sandin P (2004) The precautionary principle and the concept of precaution. Environmental Values461475.

Sansone C, Thoman DB (2005) Interest as the Missing Motivator in Self-Regulation. European Psychologist 10(3):175-186.

Sansone C, Thoman DB, Smith JL (2010) Interest and Self-Regulation. Handbook of Personality and Self-Regulation (Wiley-Blackwell) 192-217.

Scheier MF, Carver CS (1985) Optimism, coping, and health: Assessment and implications of generalized outcome expectancies. Health Psychology 4(3):219-247.

Seligman M, Csikszentmihalyi M (2000) Positive psychology: An introduction. American Psychologist 55(1):5-14.

Sheldon KM, King L (2001) Why positive psychology is necessary. American Psychologist 56(3):216217.

Silvia PJ (2008) Interest—The curious emotion. Current Directions in Psychological Science 17(1):5760.

Siponen M, Vance A (2010) Neutralization: New insights into the problem of employee information systems security policy violations. MIS Quarterly 34(3):487-502.

Smith CA, Ellsworth PC (1985) Patterns of cognitive appraisal in emotion. Journal of Personality and Social Psychology 48(4):813-838.

Smith CA, Lazarus RS (1990) Emotion and Adaptation. LA Pervin, ed. Handbook of Personality: Theory and Research (Guilford, New York, NY) 609-637.

Snyder C, Irving LM, Anderson JR (1991) Hope and health: Measuring the will and the ways. CR Snyder, DR Forsyth, eds. Handbook of Social and Clinical Psychology: The Health Perspective (Pergamon, New York, NY) 285-305.

Snyder CR, Sympson SC, Ybasco FC, Borders TF, Babyak MA, Higgins RL (1996) Development and validation of the State Hope Scale. Journal of Personality and Social Psychology 70(2):321-335.

Straub DW (1989) Validating instruments in MIS research. MIS Quarterly 13(2):147-169.

Straub DW, Boudreau MC, Gefen D (2004) Validation guidelines for IS positivist research. Communications of the Association for Information Systems 13Article 24.

Thatcher JB, Perrewé PL (2002) An empirical examination of individual traits as antecedents to computer anxiety and computer self-efficacy. MIS Quarterly 26(4):381-396. 
Twyman NW, Lowry PB, Burgoon JK, Jay F. Nunamaker J (2014) Autonomous scientifically controlled screening systems for detecting information purposely concealed by individuals. Journal of Management Information Systems 31(3):106-137.

Vance A, Lowry PB, Eggett D (2013) Using accountability to reduce access policy violations in information systems. Journal of Management Information Systems 29(4):263-289.

Vance A, Lowry PB, Eggett D (2015) A new approach to the problem of access policy violations: Increasing perceptions of accountability through the user interface. MIS Quarterly 39(2):345-366.

Venkatesh V (2000) Determinants of perceived ease of use: Integrating control, intrinsic motivation, and emotion into the technology acceptance model. Information systems research 11(4):342-365.

Wang J, Xiao N, Rao HR (2015) Research note-An exploration of risk characteristics of information security threats and related public information search behavior. Information Systems Research 26(3):619-633.

Warkentin M, Johnston AC, Walden E, Straub DW (2016) Neural Correlates of Protection Motivation for Secure IT Behaviors: An fMRI Examination. Journal of the Association for Information Systems 17(3):194-215.

Warkentin M, Willison R (2009) Behavioral and policy issues in information systems security: The insider threat. European Journal of Information Systems 18(2):101-105.

Watson D, Clark LA, Tellegen A (1988) Development and validation of brief measures of positive and negative affect: the PANAS scales. Journal of Personality and Social Psychology 54(6):1063-1070.

Williams LJ, Anderson SE (1991) Job satisfaction and organizational commitment as predictors of organizational citizenship and in-role behaviors. Journal of Management 17(3):601-617.

Willison R, Warkentin M (2013) Beyond deterrence: An expanded view of employee computer abuse. MIS Quarterly 37(1):1-20.

Workman M, Bommer WH, Straub DW (2008) Security lapses and the omission of information security measures: A threat control model and empirical test. Computers in Human Behavior 24(6):27992816.

Yi S, Baumgartner H (2004) Coping with negative emotions in purchase-related situations. Journal of Consumer Psychology 14(3):303-317.

Zhang P (2013) The affective response model: A theoretical framework of affective concepts and their relationships in the ICT context. MIS Quarterly 37(1):247-274.

Zuckerman M (1983) The distinction between trait and state scales is not arbitrary: Comment on Allen and Potkay's. Journal of Personality and Social Psychology 44(5):1083-1086.

${ }^{i}$ This distinction aligns with what Frijda (1988) called situational meaning: "Different emotions arise in response to different meaning structures" (p. 349). Discrete emotions "reflect a unique person-environment relationship and thus are associated with different goals and action tendencies designed to achieve those goals" (Nabi 2002, p. 205).

${ }^{\text {ii }}$ First, researchers never know the identity of the respondents, so the identity and privacy of respondents are guaranteed and governed by the data provider. Second, respondents' real and perceived anonymity is enhanced by having access to the survey outside of their firms' networks and computers. Providing anonymous panel surveys is highly appropriate for the elicitation of incidences of sensitive and socially undesirable behaviors such as organizational deviance (Bennett \& Robinson 2000, 2003). Panels are also appropriate for obtaining information about sensitive InfoSec behaviors, such as PMBs (Posey et al. 2013), use of organizational whistle-blowing systems (Lowry et al. 2013b), and abuse of organizational computers (Lowry \& Moody 2015). Establishing anonymity is also recommended to eliminate concerns about method-related biases (Podsakoff et al. 2003).

iii Respondents were asked the following: "When you think about protecting your organization's information and information system from security threats, to what extent do you feel ...," followed by indicators of 
discrete emotions from each quadrant of the framework of emotions. The indicators were adapted from Izard's (1977) Differential Emotions Scale, Fredrickson's (2003) Modified Differential Emotions Scale, and Venkatesh's (2000) Computer Anxiety Scale. The items measured interest (for challenge), happiness (for achievement), sadness (for loss), and anxiety (for avoidance).

iv An example item: "I usually take stressful things at work in stride" (PsyCap resilience) (Luthans et al. 2007b).

v An example of an item measuring psychological distancing: "I told myself that there was nothing I could do about the threat to my organization's information security."

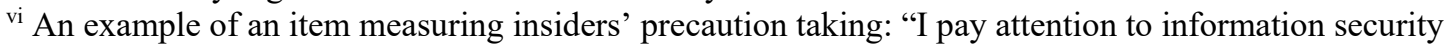
during my daily work routine."

vii Constructs defined as first- and second-order reflective appear most often in business research (Jarvis et al. 2003), and they specify that the indicators at each level reflect the latent variable (Jarvis et al. 2012; Straub et al. 2004).

The multidimensional specification of PsyCap was based on the relationships among its individual components. Luthans et al. (2007a) explained that "multidimensional constructs may have components relating to a core underlying factor whereby the shared variance or commonality between each facet comprises the higher-order factor" (p. 549). Thus, higher-order reflective specifications are appropriate when a general factor explains the correlations among the lower-order factors (Hair et al. 2014). Guided by the literature on developing second-order factor constructs (i.e., Muthén \& Muthén 1998-2010), we evaluated the lower-order factor validity and latent variable correlations for the PsyCap components. Methodologists have noted two unique validity requirements of higher-order reflective models: (1) the number of indicators should be similar across lower-order constructs, and (2) the convergence metrics (e.g., average variances extracted [AVEs] and construct reliabilities) should be met at each level of the model, but the components need not exhibit discriminance (Hair et al. 2014). All the construct reliabilities and AVEs were satisfactory (i.e., construct reliabilities ranged from 0.81 to 0.91; AVEs ranged from 0.52 to 0.63 ), indicating validity and convergence; however, the Fornell-Larcker criterion was not met, indicating a lack of discriminance (average correlation among components was 0.72). Although this result would be problematic for the evaluation of lower-order reflective constructs, it further supports modeling PsyCap as a second-order construct (Hair et al. 2014).

viii Social desirability reflects individuals' tendency to respond in a way that presents a favorable view of themselves (Vance et al. 2015). Thus, we included a construct for individuals' social desirability bias as one of our controls (Haghighat 2007). Assessment of our model indicated no significant harmful effects due to social desirability bias.

ix To capture general affectivity, the respondents were asked to "indicate to what extent you generally feel this way, that is, how you feel on average" (emphasis included in survey). The respondents rated 10 affect-related items on a 7-point Likert-type scale: five items for positive affect and five for negative affect.

${ }^{x}$ Vance et al. (2015) explained that to test mediation, three paths are evaluated simultaneously: (1) the path from the emotion to the mediating variables (path $a$ ), (2) the path from the mediating variables to precaution taking (path $b$ ), and (3) the path from the discrete emotions to precaution taking (path $c^{\prime}$ ). To evaluate mediation, we examined the $95 \%$ confidence interval for paths $a b$ and $c^{\prime}$. Where the upper and lower bounds of the $95 \%$ confidence interval for the indirect effect of paths $a b$ do not contain zero, there is mediation (MacKinnon 2008). In the case of mediation, where the $95 \%$ confidence interval for the effect of path $c^{\prime}$ contains zero, there is full mediation. Otherwise, partial mediation exists. 


\section{ONLINE APPENDIX A. DOCUMENTATION ON INSTRUMEMATION}

Table A.2. Sample Industry Statistics

\begin{tabular}{lcll}
\hline Industry & Percentage & Organization Size & Percentage \\
\hline Technology & $5.7 \%$ & Very large organization & $23.0 \%$ \\
Medical & $17.5 \%$ & i.e., More than 10,000 computers & \\
Finance and insurance & $6.4 \%$ & & \\
Education & $15.6 \%$ & Large organization & $24.4 \%$ \\
Government & $8.9 \%$ & i.e., 1,000 to 10,000 computers & \\
Retail and sales & $8.4 \%$ & & \\
Industrial, manufacturing, and & $16.0 \%$ & Medium organization & $25.7 \%$ \\
transportation & $3.5 \%$ & i.e., 100 to 1,000 computers & \\
Hospitality & $7.4 \%$ & Small organization & $26.9 \%$ \\
Professional services & $10.6 \%$ & i.e., 1 to 100 computers & \\
Other & & & \\
\hline
\end{tabular}




\section{ONLINE APPENDIX B. DOCUMENTATION ON INSTRUMEMATION}

Table B.1. Measures in Study

\begin{tabular}{|c|c|c|c|}
\hline Items (Citation) & Prompts and Measures ${ }^{i}$ & Mean & SD \\
\hline \multirow[t]{4}{*}{$\begin{array}{l}\text { Interest (Izard 1977) } \\
\text { (Fredrickson et al. } \\
\text { 2003) }\end{array}$} & $\begin{array}{l}\text { Instructions: "When you think about protecting your } \\
\text { organization's information and information system from } \\
\text { security threats, to what extent do you feel..." }{ }^{b}\end{array}$ & & \\
\hline & 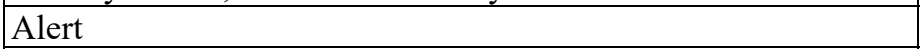 & 3.86 & 1.80 \\
\hline & Curious & 2.89 & 1.73 \\
\hline & Interested & 3.70 & 1.80 \\
\hline \multirow[t]{4}{*}{$\begin{array}{l}\text { Happiness } \\
\text { (Fredrickson et al. } \\
\text { 2003; Izard 1977) }\end{array}$} & $\begin{array}{l}\text { Instructions: "When you think about protecting your } \\
\text { organization's information and information system from } \\
\text { security threats, to what extent do you feel..." b }\end{array}$ & & \\
\hline & Glad & 3.54 & 1.96 \\
\hline & Happy & 3.53 & 1.94 \\
\hline & Joyful & 3.00 & 1.87 \\
\hline \multirow[t]{4}{*}{$\begin{array}{l}\text { Sadness (Fredrickson } \\
\text { et al. 2003; Izard } \\
\text { 1977) }\end{array}$} & $\begin{array}{l}\text { Instructions: "When you think about protecting your } \\
\text { organization's information and information system from } \\
\text { security threats, to what extent do you feel..." b }\end{array}$ & & \\
\hline & Sad & 1.84 & 1.28 \\
\hline & Unhappy & 1.90 & 1.32 \\
\hline & Discouraged & 2.04 & 1.33 \\
\hline \multirow[t]{4}{*}{$\begin{array}{l}\text { Anxiety (Venkatesh } \\
\text { 2000) }\end{array}$} & $\begin{array}{l}\text { Instructions: "When you think about protecting your } \\
\text { organization's information and information system from } \\
\text { security threats, to what extent do you feel..." b }\end{array}$ & & \\
\hline & Nervous & 2.19 & 1.43 \\
\hline & Threatened & 2.13 & 1.38 \\
\hline & Uneasy & 2.16 & 1.39 \\
\hline \multirow{7}{*}{$\begin{array}{l}\text { PsyCap hope } \\
\text { (PCH) } \\
\text { (Luthans et al. 2007) }\end{array}$} & $\begin{array}{l}\text { Instructions: "Please indicate your level of agreement with the } \\
\text { following statements." a }\end{array}$ & & \\
\hline & $\begin{array}{l}\text { PCH-1. If I should find myself in a jam at work, I could think of } \\
\text { many ways to get out of it. }\end{array}$ & 5.40 & 1.07 \\
\hline & $\begin{array}{l}\text { PCH-2. At the present time, I am energetically pursuing my } \\
\text { work goals. }\end{array}$ & 5.14 & 1.30 \\
\hline & PCH-3. There are lots of ways around any problem. & 5.48 & 1.11 \\
\hline & $\begin{array}{l}\text { PCH-4. Right now I see myself as being pretty successful at } \\
\text { work. }\end{array}$ & 5.48 & 1.16 \\
\hline & $\begin{array}{l}\text { PCH-5. I can think of many ways to reach my current work } \\
\text { goals. }\end{array}$ & 5.39 & 1.13 \\
\hline & $\begin{array}{l}\text { PCH-6. At this time, I am meeting the work goals that I set for } \\
\text { myself. }\end{array}$ & 5.53 & 1.21 \\
\hline \multirow[t]{5}{*}{$\begin{array}{l}\text { PsyCap resilience } \\
\text { (PCR) }\end{array}$} & $\begin{array}{l}\text { Instructions: "Please indicate your level of agreement with the } \\
\text { following statements." a }\end{array}$ & & \\
\hline & $\begin{array}{l}\text { PCR-2. I usually manage difficulties one way or another at } \\
\text { work. }\end{array}$ & 5.60 & .98 \\
\hline & PCR-3. I can be "on my own," so to speak, at work if I have to. & 5.92 & 1.09 \\
\hline & $\begin{array}{l}\text { PCR-5. I can get through difficult times at work because I've } \\
\text { experienced difficulty before. }\end{array}$ & 5.54 & 1.05 \\
\hline & PCR-6. I feel I can handle many things at a time at this job. & 5.63 & 1.08 \\
\hline
\end{tabular}




\begin{tabular}{|c|c|c|c|}
\hline \multirow{5}{*}{\begin{tabular}{|l|} 
PsyCap optimism \\
(PCO) \\
(Luthans et al. 2007)
\end{tabular}} & $\begin{array}{l}\text { Instructions: "Please indicate your level of agreement with the } \\
\text { following statements." a }\end{array}$ & & \\
\hline & $\begin{array}{l}\text { PCO-1. When things are uncertain for me at work, I usually } \\
\text { expect the best. }\end{array}$ & 4.56 & 1.37 \\
\hline & $\begin{array}{l}\text { PCO-3. I always look on the bright side of things regarding my } \\
\text { job. }\end{array}$ & 4.96 & 1.32 \\
\hline & $\begin{array}{l}\text { PCO-4. I'm optimistic about what will happen to me in the } \\
\text { future as it pertains to work. }\end{array}$ & 5.10 & 1.35 \\
\hline & $\begin{array}{l}\text { PCO-6. I approach this job as if "every cloud has a silver } \\
\text { lining." }\end{array}$ & 4.87 & 1.27 \\
\hline \multirow[t]{7}{*}{$\begin{array}{l}\text { PsyCap self-efficacy } \\
\text { (PCSE) }\end{array}$} & $\begin{array}{l}\text { Instructions: "Please indicate your level of agreement with the } \\
\text { following statements." a }\end{array}$ & & \\
\hline & $\begin{array}{l}\text { PCE-1. I feel confident analyzing a long-term problem to find a } \\
\text { solution. }\end{array}$ & 5.44 & 1.17 \\
\hline & $\begin{array}{l}\text { PCE-2. I feel confident in representing my work area in } \\
\text { meetings with management. }\end{array}$ & 5.42 & 1.33 \\
\hline & $\begin{array}{l}\text { PCE-3. I feel confident contributing to discussions about the } \\
\text { company's strategy. }\end{array}$ & 5.08 & 1.43 \\
\hline & $\begin{array}{l}\text { PCE-4. I feel confident helping to set targets/goals in my work } \\
\text { area. }\end{array}$ & 5.44 & 1.25 \\
\hline & $\begin{array}{l}\text { PCE-5. I feel confident contacting people outside the company } \\
\text { (e.g., suppliers, customers) to discuss problems. }\end{array}$ & 5.15 & 1.48 \\
\hline & $\begin{array}{l}\text { PCE-6. I feel confident presenting information to a group of } \\
\text { colleagues. }\end{array}$ & 5.45 & 1.33 \\
\hline \multirow[t]{4}{*}{$\begin{array}{l}\text { Psychological } \\
\text { distancing (PD) } \\
\text { (Beaudry \& } \\
\text { Pinsonneault 2010) }\end{array}$} & $\begin{array}{l}\text { Instructions: "Please indicate the extent to which you reacted in } \\
\text { the following ways when confronted with a potential threat to } \\
\text { your organization's information security in the last year. (If you } \\
\text { have been with your organization for less than a year, this } \\
\text { concerns the entire time you have been with your } \\
\text { organization)." c }\end{array}$ & & \\
\hline & $\begin{array}{l}\text { PD-1. I tried not to worry about the threat to my organization's } \\
\text { information security. }\end{array}$ & 2.90 & 1.73 \\
\hline & $\begin{array}{l}\text { PD-2. I told myself that there was nothing I could do about the } \\
\text { threat to my organization's information security. }\end{array}$ & 2.90 & 1.70 \\
\hline & $\begin{array}{l}\text { PD-3. I told myself that time would take care of the threat to my } \\
\text { organization's information security. }\end{array}$ & 3.59 & 1.73 \\
\hline \multirow[t]{4}{*}{$\begin{array}{l}\text { Precaution taking (PT) } \\
\text { (Boss et al. 2009) }\end{array}$} & $\begin{array}{l}\text { Instructions: "Please indicate your level of agreement with the } \\
\text { following statements." a }\end{array}$ & & \\
\hline & $\begin{array}{l}\text { PT-1. I pay attention to information security during my daily } \\
\text { work routine. }\end{array}$ & 5.05 & 1.63 \\
\hline & $\begin{array}{l}\text { PT-2. I keep aware of the latest information security threats so I } \\
\text { can protect my organization's information. }\end{array}$ & 4.54 & 1.72 \\
\hline & $\begin{array}{l}\text { PT-3. My organization's information is as secure as I can make } \\
\text { it. }\end{array}$ & \begin{tabular}{|l|}
5.33 \\
\end{tabular} & 1.35 \\
\hline
\end{tabular}

iAll scaling was 7-point Likert-type scaling with three different sets of anchors to help prevent common methods bias; ${ }^{a}$ anchors are "Strongly Disagree-Strongly Agree"; ${ }^{b}$ anchors are "Not at all-Completely"; c anchors are "Never-Always." 


\section{ONLINE APPENDIX C. COMMON-METHOD VARIANCE ANALYSES}

As previous literature describes (Burns et al. 2017; Richardson et al. 2009; Williams et al. 2010), to conduct a formal test of CMV, we ran a series of CFAs:

1. A totally free model.

2. A baseline model that restrains the correlations between the substantive items and the marker variable to zero and constrains the loadings of the marker items onto the marker variable and the marker-variable error terms to the unstandardized results from the totally free model.

3. A method-C model that is the same as the baseline except that it constrains the factor loadings from the marker variable to each substantive item to be equal to one another.

4. A method-R model that is the same as method $\mathrm{C}$, except that the correlations among the substantive variables are constrained to the unstandardized correlations from the baseline model.

To test for CMV, we tested the fit of the CFAs for the following models for significant differences:

1. We tested the baseline model for significantly different fit from the method-C model. If method-C had significantly better fit, it indicated CMV.

2. We tested the method-R model fit for significantly different fit from the method-C model. If method-R fit was worse than method-C fit, there was evidence of bias due to CMV.

To assess the implications of CMV in our sample, we included five variables in our marker-variable technique: four substantive variables and our marker variable. As in prior CMV analyses (Burns et al. 2017), our marker variable measures attitude toward the color blue with a three-item scale (Cronbach's $\alpha=0.838$ ). For our substantive variables, we included two emotions and two endogenous variables (i.e., happiness, sadness, psychological distancing, and precaution taking). The results of the CFA marker-variable technique indicate that CMV is not an issue for the current study. The results appear in Table B.1.

Table B.1. CFA Marker-Variable Results

\begin{tabular}{lllll}
\hline Model & Model Fit & Model Comparison & CFI & Result \\
\hline Baseline Model & $\begin{array}{l}\mathrm{X}^{2}=150.376 \\
\text { d.f. }=90\end{array}$ & 0.983 & \\
Method-C & $\begin{array}{l}\mathrm{X}^{2}=149.57 \\
\text { Model }\end{array}$ & $\begin{array}{l}\text { Baseline vs. Method-C } \\
\Delta \mathrm{X}^{2}=0.806 ; \text { d.f. }=1 ;(p=0.37)\end{array}$ & 0.983 & No CMV detected \\
$\begin{array}{l}\text { Method-R } \\
\text { Model }\end{array}$ & $\begin{array}{l}\mathrm{X}^{2}=149.58 \\
\text { d.f. }=95\end{array}$ & $\begin{array}{l}\text { Method-C vs. Method-R } \\
\Delta \mathrm{X}^{2}=0.01 ; \text { d.f. }=6(p=0.999)\end{array}$ & 0.985 & $\begin{array}{l}\text { No bias from CMV } \\
\text { detected }\end{array}$ \\
\hline
\end{tabular}

\section{REFERENCES FOR ONLINE APPENDIX}

Beaudry A, Pinsonneault A (2010) The other side of acceptance: Studying the direct and indirect effects of emotions on information technology use. MIS Quarterly 34(4):689-710.

Boss SR, Kirsch LJ, Angermeier I, Shingler RA, Boss RW (2009) If someone is watching, I'll do what I'm asked: Mandatoriness, control, and information security. European Journal of Information Systems 18(2):151-164.

Burns AJ, Posey C, Roberts TL, Benjamin Lowry P (2017) Examining the relationship of organizational insiders' psychological capital with information security threat and coping appraisals. Computers in Human Behavior 68(March):190-209.

Fredrickson BL, Tugade MM, Waugh CE, Larkin GR (2003) What good are positive emotions in crises? A prospective study of resilience and emotions following the terrorist attacks on the United States on September 11th, 2001. Journal of Personality and Social Psychology 84(2):365-376.

Izard CE (1977) Human emotions, (Springer, New York, New York).

Luthans F, Youssef CM, Avolio BJ (2007) Psychological Capital: Developing the Human Competitive Edge (Kindle Edition), (Oxford University Press, New York, NY). 
Richardson HA, Simmering MJ, Sturman MC (2009) A tale of three perspectives. Organizational Research Methods 12(4):762-800.

Venkatesh V (2000) Determinants of perceived ease of use: Integrating control, intrinsic motivation, and emotion into the technology acceptance model. Information systems research 11(4):342-365.

Williams LJ, Hartman N, Cavazotte F (2010) Method variance and marker variables: A review and comprehensive CFA marker technique. Organizational Research Methods 13(3):477-514. 